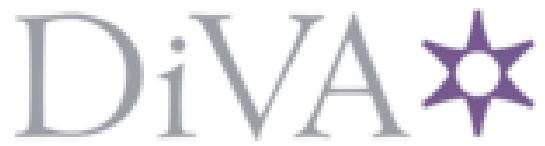

http://www.diva-portal.org

Preprint

This is the submitted version of a paper published in Electrochimica Acta.

Citation for the original published paper (version of record):

Granqvist, C G., Arvizu, M A., Bayrak Pehlivan, I., Qu, H-Y., Wen, R-T. et al. (2018) Electrochromic materials and devices for energy efficiency and human comfort in buildings: A critical review

Electrochimica Acta, 259: 1170-1182

https://doi.org/10.1016/j.electacta.2017.11.169

Access to the published version may require subscription.

N.B. When citing this work, cite the original published paper.

Permanent link to this version:

http://urn.kb.se/resolve?urn=urn:nbn:se:uu:diva-350203 


\title{
Electrochromic materials and devices for energy efficiency and human comfort in buildings: a critical review
}

C. G. Granqvist, ${ }^{\mathrm{a}, *}$ M. A. Arvizu, ${ }^{\mathrm{a}}$ İ. Bayrak Pehlivan, ${ }^{\mathrm{a}}$ H.-Y. Qu, ${ }^{\mathrm{a}, \mathrm{b}}$ R.-T. Wen, ${ }^{\mathrm{a}}$ and G. A. Niklasson $^{\mathrm{a}}$

${ }^{a}$ Department of Engineering Sciences, The Angström Laboratory, Uppsala University, PO Box 534, SE-75121 Uppsala, Sweden

${ }^{\mathrm{b}}$ MIIT Key Laboratory of Critical Materials Technology for New Energy Conversion and Storage, School of Chemistry and Chemical Engineering, Harbin Institute of Technology, 150001 Harbin, China

\begin{abstract}
Electrochromic (EC) materials can be integrated in thin-film devices and used for modulating optical transmittance. The technology has recently been implemented in large-area glazing (windows and glass facades) in order to create buildings which combine energy efficiency with good indoor comfort. This critical review describes the basics of EC technology, provides a case study related to EC foils for glass lamination, and discusses a number of future aspects. Ample literature references are given with the object of providing an easy entrance to the burgeoning research field of electrochromics.
\end{abstract}

*E-mail address: claes-göran.granqvist@angstrom.uu.se 


\section{Introduction}

Electrochromic (EC) materials are characterized by properties that can be tuned, persistently and reversibly, through the application of electrical current or voltage $[1,2]$. These materials, and their associated device technologies, are rapidly evolving especially with regard to implementation in windows and glass facades - jointly known as glazing-for energy-efficient buildings with good indoor comfort. This paper outlines the state-of-the-art for oxide-based electrochromics and points at some recent advances and possible future developments.

Environmental challenges provide a driving force for many of today's (2017) studies of EC materials. Underlying these challenges is the fact that human actions lead to the injection of about 10 billion tonnes of carbon into the atmosphere per year [3] some half of which ends up in the air. It is therefore to be expected that the carbon dioxide content of the Earth's atmosphere is rising swiftly; this content was $\sim 315 \mathrm{ppm}$ in the late 1950s and currently exceeds $\sim 400 \mathrm{ppm}$ [4]. The increased amount of $\mathrm{CO}_{2}$ originates from energy productionmostly the burning of coal, oil and gas - and is generally believed to affect life on Earth and yield global warming and rising sea levels [5]. There are also numerous secondary and harmful effects of climate change related to socio-economic effects and enhanced risk for violent conflict [6,7], health issues [8], and alterations of the biosphere [9,10] and geosphere [11]. Furthermore, it should be emphasized that the global population is rising and forecast to be $50 \%$ larger in 2100 than today [12], and this population is increasingly located in megacities which act as "urban heat islands" with temperatures several degrees higher of those in the neighbouring countryside [13].

The energy-population nexus makes it patently clear that the Earth's energy production must be decarbonized, which stresses the importance of better buildings. In fact, today's building stock is responsible for $30-40 \%$ of the global use of primary energy [14]. Furthermore, the role of buildings is currently growing in many countries, and their part of the energy consumption in the USA, to take one example, was $34 \%$ in 1980 but as large as $41 \%$ in 2010 [15].

Energy efficiency in the built environment has often been neglected as an opportunity for $\mathrm{CO}_{2}$ abatement [16], but recent European developments [17] highlight its importance. In fact, there are many "green" technologies, often with nano features, that can be put to work in order to create better buildings [18-26] and which also can lead to economic growth [27], and energy-efficient glazing stands out as one of the most interesting possibilities. The glazing 
often allows huge energy flows to enter or exit a building, which means that energy-guzzling cooling or heating must be used to create a comfortable indoor environment. One solution to this conundrum is to minimize the size of the glazing, but this leads to unacceptable losses of precious indoors-outdoors contact and day-lighting. However, energy efficiency can be reached with glazing allowing tunable transmittance of solar energy and visible light. This type of glazing is often called "smart" or "intelligent" [28] and is based on "chromogenic" materials $[29,30]$, with EC materials currently being the most widely studied and important option [31].

EC materials can be altered electrically and can be used in devices for automatically adjusted as well as operator-controlled transmittance of solar energy and visible light $[1,2]$. These properties allow many benefits, as extensively investigated; current studies have focused on energy efficiency [32-39], lowered $\mathrm{CO}_{2}$ emission [40], and on indoor comfort [41-43] for the users of buildings with EC glazing. These assets can be combined with financial benefits for the operators of the buildings [44]. EC glazing was proposed already in $1984[45,46]$ and was introduced on the market during the 2010s. An increasing number of EC installations are currently used in real-life situations [31,47-49]. Oxide-based EC materials are far from the only alternatives for "smart" glazings [31], but it appears that they are currently the main ones used in buildings. Other options include devices based on reversible electroplating [50], suspended particles [51], polymer-dispersed liquid crystals [52], metal hydrides [53], plasmonic effects in wide-bandgap electrically conducting nanoparticles [54-56], and solution-based systems [57]. It should also be noted that oxidebased materials are far from the only ones with EC properties and, in particular, there are a plethora of organic EC materials [58-61]. The latter ones are particularly well suited for display devices but most probably lack sufficient durability for uses in buildings.

It is important to understand that EC-based glazing must be compatible with truly largescale manufacturing. Thus flat-glass production, mostly by the float process, has been predicted to reach a stunning $11.5 \times 10^{9}$ square meters per year in 2018 [62]. Implementing EC-based functionality on only a very small fraction of the World's glazing necessitates coating technology with manufacturing equipment capable of handling square kilometers each year.

EC materials and devices must be characterized as to their ability to transmit and reflect luminous (visible) and solar radiation. These properties can be introduced by considering the spectra shown in Fig. 1. Thermal radiation, in panel (a), is governed by blackbody curves- 
which are shown for four temperatures - multiplied by an empirical emittance less than one; clearly this radiation is at $\lambda>2 \mu \mathrm{m}$ for normal ambient temperatures, where $\lambda$ denotes wavelength. Solar radiation falling onto the Earth's atmosphere can be represented by blackbody-like radiation for the Sun's surface temperature $\left(5505^{\circ} \mathrm{C}\right)$ and lies at $0.2<\lambda<3$ $\mu \mathrm{m}$. At ground level, and for normal clear weather, this radiation is as shown in Fig. 1(b); the distinct minima emanate from molecular absorption. Luminous radiation, finally, is described by the curve in Fig. 1(b) which covers the $0.4<\lambda<0.7 \mu \mathrm{m}$ range and is peaked at $0.55 \mu \mathrm{m}$. Quantitative luminous (lum) and solar (sol) transmittance, indicated by $T_{\text {lum }}$ and $T_{\text {sol }}$, respectively, can be calculated from

$$
T_{\text {lum,sol }}=\int \mathrm{d} \lambda \varphi_{\text {lum,sol }}(\lambda) T(\lambda) / \int \mathrm{d} \lambda \varphi_{\text {lum }, \text { sol }}(\lambda),
$$

where $T(\lambda)$ is spectral transmittance, $\varphi_{\text {lum }}$ is the eye's spectral sensitivity [63] and $\varphi_{\text {sol }}$ signifies an "air mass 1.5 " solar irradiance spectrum (with the sun being $37^{\circ}$ above the horizon) [64].

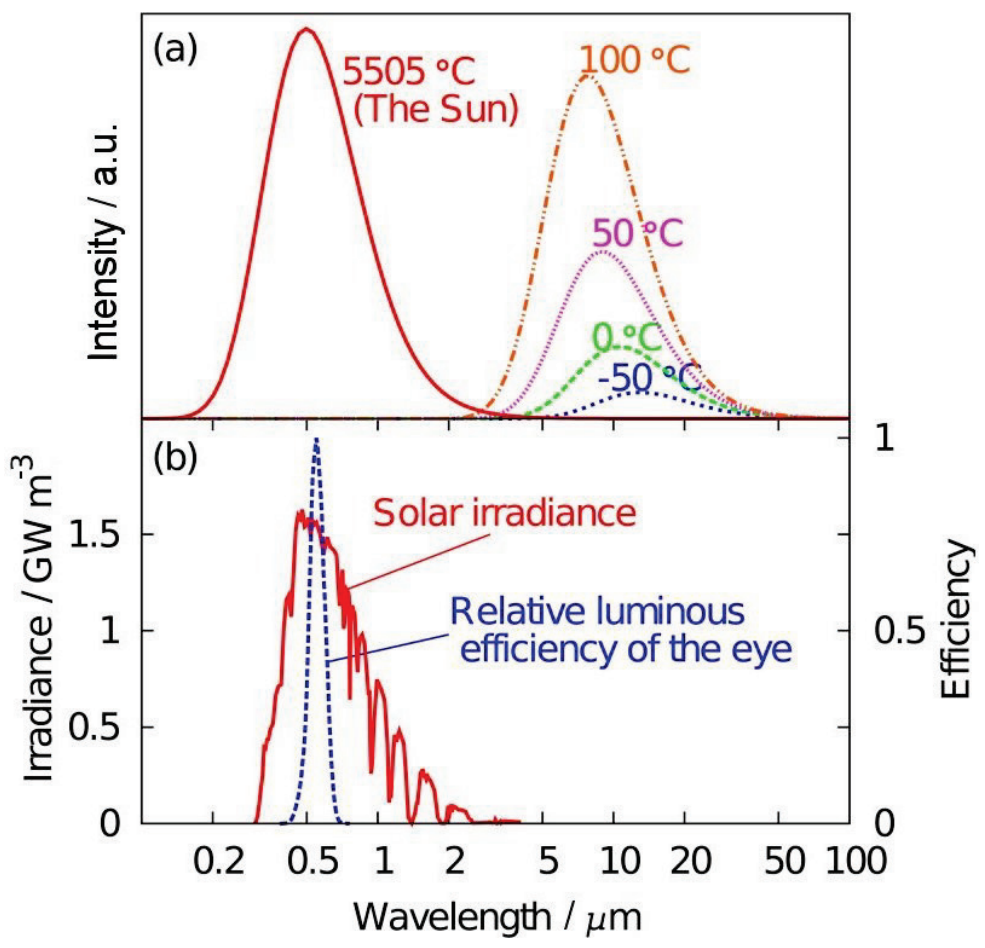

Fig. 1. (a) Blackbody spectra for the shown temperatures (note that the vertical scales are different for blackbody and solar spectra). (b) Typical solar irradiance spectrum for clear weather, and relative spectral sensitivity of a light-adapted eye.

Many reviews have been written on EC materials and devices. The present paper is an update and extension of some recent surveys both regarding general content and references $[31,65,66]$. 


\section{Operating principles and materials for electrochromics}

\subsection{Generic device design}

Electrochromics is conveniently understood from a device perspective, and Fig. 2 illustrates a generic EC design [1,67] with five superimposed layers either on a single substrate or positioned between two substrates as a laminate. Glass is most commonly used as substrate material, but plastics is an alternative and flexible foils of polyethylene terephthalate (PET) allow device fabrication by roll-to-roll technology as discussed in Sec. 3 below [6871].

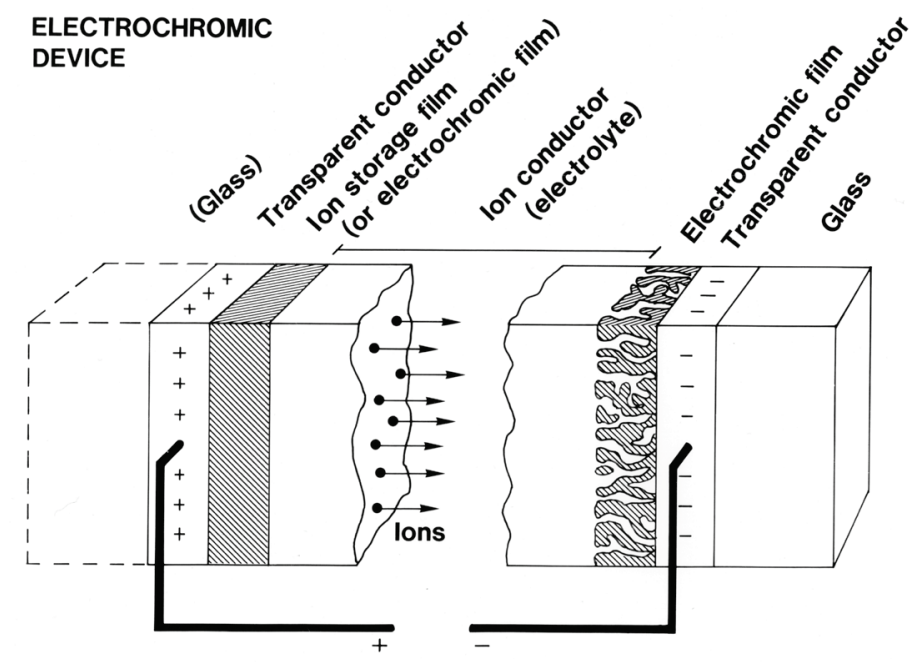

Fig. 2. Generic EC device design; arrows illustrate the transport of positive ions in an electrical field. The dashed lines to the left indicate that the device can comprise either a five-layer stack on a single substrate or a laminate structure with two substrates. The ion storage film in a practical device may have EC properties.

The central part of an EC device conducts ions but is an insulator for electrons. It can be a polymer electrolyte layer $[72,73]$ or a transparent thin film. The ions should be small in order to be easily transported in an electric field; protons $\left(\mathrm{H}^{+}\right)$and lithium ions $\left(\mathrm{Li}^{+}\right)$are by far the most common alternatives.

The ion conductor is in contact with an EC thin film which is a mixed conductor and conducts ions as well as electrons. Tungsten oxide is the premier example; it is the first widely known EC material [74] and is commonly employed in today's EC glazing [31]. The other side of the pure ion conductor has an ion storage film which again is a mixed conductor. It is preferable that the ion storage film has EC properties complementary to those of the first 
EC film. The mentioned three-layer construction is located between transparent electrical conductors, which can be of many kinds and use thin films of doped wide-bandgap semiconductors or noble metals, carbon nanotubes or graphene layers, noble-metal nanowires, layers of some organics, or hybrids of two or more of the mentioned alternatives $[31,75,76]$. Certain interfacial layers can improve the EC functionality [77,78].

If a voltage is applied between the transparent conductors, there can be ion transport between the EC film and the ion storage film, and this charge is balanced by electrons introduced into or ejected from the EC film and the ion storage film by way of the transparent conductors. These electrons are responsible for the optical modulation of the EC film, as elaborated below. Reversing the voltage or, for some materials combinations, short-circuiting recovers the original optical properties. EC devices normally maintain their physical properties in the absence of an applied voltage - i.e., under open-circuit conditions - so that the coloration can be aborted at any intermediate level between two extrema. It then follows that electrical power is needed solely to change the optical performance, which leads to energy efficiency of the EC glazing. Open-circuit memory is contingent on extremely low electron conductivity of the central ion-conducting layer, which is easier to reach with a polymer electrolyte, with a characteristic thickness of several micrometers, than in a usually much thinner inorganic ion-conducting film. The voltage needed for ion transport is typically only a few volt dc, which allows simple powering for example by photovoltaic cells integrated in the EC device [79].

An EC device is obviously akin to an electrical battery, whose charging state is manifested as optical absorption. This analogy can be useful-yet it is seldom taken advantage of sufficiently - and EC devices and electrical batteries often share the same limitations and idiosyncrasies. Thus both kinds of devices degrade rapidly upon overcharging but they can also show "self-repair", and rejuvenation of several types of EC oxides has recently been demonstrated under galvanostatic and potentiostatic treatment, as further discussed in Sec. 4.2 [80,81]. Furthermore, both batteries and EC devices are unable to change their properties instantaneously, and a full-size EC glazing may take tens of minutes to transition from fully dark to fully transparent state.

As observed above, it is suitable to have a thin-film counter electrode whose optical properties complement those of the EC film. Such complementarity is possible since there are EC oxides of two types: some darkening under ion insertion and called "cathodic" and other ones darkening under ion extraction and referred to as "anodic". Oxides based on W, Mo, Ti 
and $\mathrm{Nb}$ are cathodic while oxides based on $\mathrm{Ni}$ and $\mathrm{Ir}$ are anodic [1,31]. An intermediate situation prevails for $\mathrm{V}_{2} \mathrm{O}_{5}$ which exhibits anodic and cathodic features in different wavelength ranges [82-84]. Oxides based on $\mathrm{Cr}, \mathrm{Mn}, \mathrm{Fe}, \mathrm{Co}, \mathrm{Cu}, \mathrm{Rh}$ and $\mathrm{Ta}$ can display some electrochromism but are unable to reach a fully bleached state and/or have weak electrochromism and therefore are largely irrelevant for practical applications. Mixed EC oxides can exhibit properties better than those of the individual components. EC devices comprising W-oxide-based and Ni-oxide-based thin films are especially interesting $[85,86]$ and are used in several varieties of EC glazing [31], including those discussed shortly in Sec. 3. Shuttling electrical charge from $\mathrm{Ni}$ oxide to $\mathrm{W}$ oxide makes both of these films dark, whereas both films become transparent when the charge is returned. Furthermore, the spectral coloration of $\mathrm{W}$ oxide and $\mathrm{Ni}$ oxide is complementary and can yield a fairly neutral color in an EC device, which is a desirable feature for most glazing.

\subsection{The role of nanostructure}

Nanostructure is important for EC materials and involves several length scales. These aspects are discussed next with particular reference to $\mathrm{W}$ oxide, which has been studied in depth. It is first observed that most of EC oxides can be viewed as being composed from octahedral structural units arranged with various degrees of corner-sharing and edge-sharing [1]. This is a benign structure since inter-octahedral spaces are large enough to allow at least some ion transport.

For stoichiometric $\mathrm{WO}_{3}$, the simplest structure comprises corner-sharing octahedra each with a centrally positioned tungsten atom surrounded by six oxygen atoms. However, this cubic structure is an oversimplification, and a monoclinic or triclinic structure is applicable for bulk-like $\mathrm{WO}_{3}$ at normal temperature and pressure. The latter structures are more suitable for ion transport than the cubic one since the distances between the octahedral units are larger. Hexagonal structures are readily formed in thin films, nanorods and nanowires of $\mathrm{W}$ oxide [31], and this structure is even better for ion transport.

Empirical information on nanostructures in $\mathrm{W}$ oxide thin films have been reported many times in the scientific literature, and particularly clear information has been obtained for evaporated and sputter deposited W oxide films investigated by X-ray spectroscopy $[87,88]$. In the case of evaporated films, cluster-type structures were apparent and were based on hexagonal-like units which grew in size and interconnectivity for film deposition onto 
substrates with successively higher temperatures [87]. These results are in agreement with the fact that trimeric $\mathrm{W}_{3} \mathrm{O}_{9}$ molecules tend to form during evaporation [89] and also with computed lowest-energy structures of $\left(\mathrm{WO}_{3}\right)_{q}$ clusters [90]. Sputtered films appear to be even more disordered and detailed structural models have been obtained from reverse Monte-Carlo modelling of extended X-ray absorption fine structure data [88]; these films can be described as a mixture of corner-sharing and a small amount of edge-sharing polyhedra, with five-fold and a small number of four-fold coordinated $\mathrm{W}$ atoms present in addition to the six-fold ones. EC films are often described as "amorphous, but it is clear that some local order prevails, at least on the level of the polyhedral structural units, even when the films are deposited onto substrates at room temperature. Local order may be decreased under Li ion insertion [91].

Some ion transport is possible in the structures discussed above, but it is nevertheless important to prepare films with a sufficient degree of porosity in order to enable facile ion mobility. Many deposition techniques may be able to produce thin films with the desired properties, with greater or smaller difficulty. Considering sputter deposition, which is usually employed for the manufacturing of EC glazing, it is illustrative to consider "zone diagrams" which describe characteristic structural features as a function of deposition conditions such as the pressure of the sputter plasma and the substrate temperature in relation to the melting point of the deposited material [92-94]. Relatively high pressure in the sputter plasma, together with low substrate temperature, are appropriate and lead to films with what is known as "zone 1" structure with columnar features. Tungsten oxide films produced by sputter deposition under such conditions typically exhibits porosities of 20 to $30 \%$. Even greater porosity can be achieved by oblique-angle deposition - with large angle between the direction of the impinging species and the substrate's surface normal $[95,96]$ —as clearly shown for Woxide-based EC films [97]. Rapid EC dynamics is often reported for small-area coatings with "zone 1" character and is assigned to the nanostructure $[98,99]$.

A discussion on suitable nanostructures for EC thin films also have to include the influence of the surface of the film, and recent work has pointed to the importance of surface features, including deposition-dependent exposed crystal facets, for anodically coloring $\mathrm{Ni}$ oxide immersed in Li-ion conducting electrolytes [100].

\subsection{Optical properties}


The origin of the optical absorption in EC oxides has been investigated for many years. This is a complicated topic for various reasons and only a simplified view, capturing the most salient features, is given here. The complications ensue from the absence of a well-defined crystal structure, as observed above, and also from oxygen deficiency and inclusion of mobile ions and water molecules. Nevertheless, a detailed picture has been presented for $\mathrm{W}$ oxide [101-105], while much less is known for Ni oxide and other EC oxides.

Insertion and extraction of protons $\left(\mathrm{H}^{+}\right)$and electrons $\left(e^{-}\right)$in $\mathrm{WO}_{3}$ can be described by the highly simplified electrochemical reaction

$$
\left[\mathrm{WO}_{3}+\mathrm{H}^{+}+e^{-}\right]_{\text {bleached }} \leftrightarrow\left[\mathrm{HWO}_{3}\right]_{\text {colored }},
$$

where $\mathrm{H}^{+}$can be replaced by $\mathrm{Li}^{+}$or some other ion [1]. Complete reversibility can only be achieved for partial reactions [80,106,107], which implies that the colored material should be written $\mathrm{H}_{x} \mathrm{WO}_{3}$ or $\mathrm{Li}_{x} \mathrm{WO}_{3}$ with $x<0.5$. For Ni oxide, the corresponding reaction is

$$
\left[\mathrm{Ni}(\mathrm{OH})_{2}\right]_{\text {bleached }} \leftrightarrow\left[\mathrm{NiOOH}+\mathrm{H}^{+}+e^{-}\right]_{\text {colored }},
$$

where the reaction is believed to take place on hydrous grain boundaries $[108,109]$. If $\mathrm{Li}^{+}$is the mobile ionic species, the reaction is confined to the surface [100], as already observed.

The fact that most EC oxides can be represented as being constructed from octahedra-like structural units makes it possible to put forward a schematic model for the occurrence of cathodic and anodic electrochromism [1]. The oxides can be characterized by oxygen $2 p$ bands well separated from the metal $d$ band, and octahedral symmetry leads to a splitting of the latter band into sub-bands with the conventional designations $e_{g}$ and $t_{2 g}$ [110]. Fig. 3 shows three cases of relevance for EC oxides. Specifically, the left-hand panel, for $\mathrm{H}_{x} \mathrm{WO}_{3}$, shows an $\mathrm{O} 2 p$ band that is separated from a split $d$ band by an energy gap. Stoichiometric $\mathrm{WO}_{3}$ has a full $\mathrm{O} 2 p$ band and an empty $d$ band, and the band gap is wide enough to give luminous transmittance for thin films. Insertion of ions and charge balancing electrons yields partial filling of the $d$ band along with optical absorption as discussed shortly. Middle panel of Fig. 3 pertains to anodically coloring EC oxides, such as $\mathrm{IrO}_{2}$ and overstoichiometric Ni oxide $\left(\mathrm{NiO}_{x}\right.$ with $\left.x>1\right)$, which can be described as having unoccupied $t_{2 g}$ states, and the insertion of ions and electrons may fill these states to the top of the band implying that the material displays a gap between the $e_{g}$ and $t_{2 g}$ sub-bands. The material then becomes transparent, assuming that the band gap is sufficiently large. Finally, the right-hand part of Fig. 3 indicates that $\mathrm{V}_{2} \mathrm{O}_{5}$, with both cathodic and anodic characteristics, has a principally different electronic structure. The departure from octahedral coordination is large enough that the $d$ band exhibits 
a narrow split-off part in the band gap. Insertion of ions and electrons into $\mathrm{V}_{2} \mathrm{O}_{5}$ can fill this narrow band so that the optical band gap is broadened. This feature of the band structure can account for electrochromism in $\mathrm{V}_{2} \mathrm{O}_{5}$ [82] as well as band gap widening upon photo-injection of hydrogen into $\mathrm{V}_{2} \mathrm{O}_{5}$ [111].

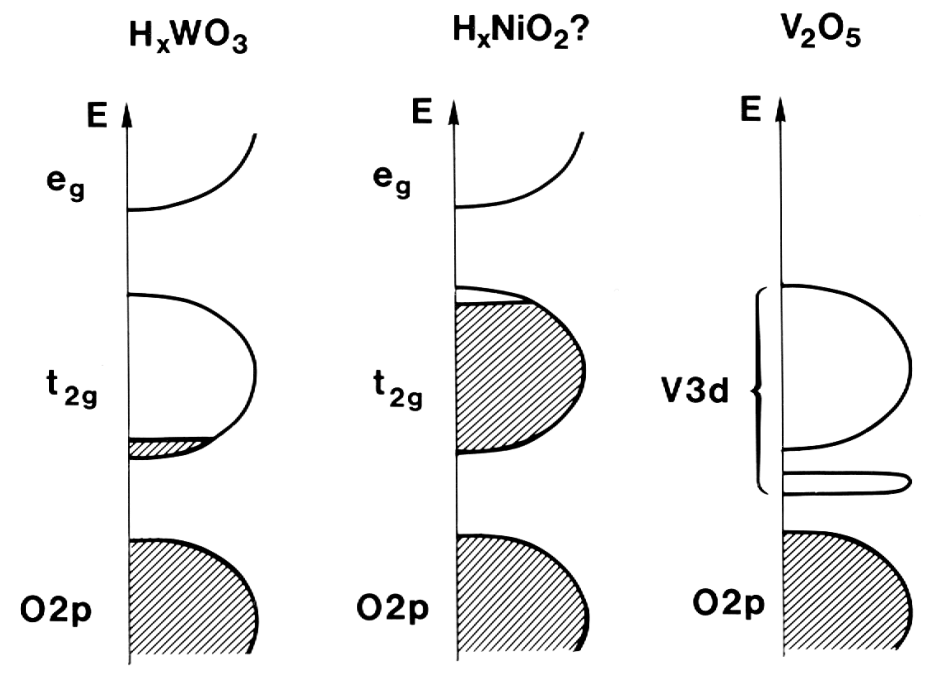

Fig. 3. Schematic band structures for different types of EC oxides. Shaded areas indicate filled states and $E$ is energy. The pertinent chemical species are indicated at the top; some uncertainty prevails for the Ni-containing species.

The detailed mechanism of optical absorption is considered next, again with particular consideration of $\mathrm{W}$ oxide. When ions and electrons are inserted, the electrons become localized on tungsten sites, and some of the $\mathrm{W}^{6+}$ sites turn into $\mathrm{W}^{5+}$ sites. By absorption of a photon, the inserted electrons can obtain sufficient energy to be transferred to a neighboring site. Transfer between two sites, denoted $i$ and $j$, can be described, schematically, as $[1,112,113]$

$$
\mathrm{W}_{i}^{5+}+\mathrm{W}_{j}^{6+}+\text { photon } \rightarrow \mathrm{W}_{i}^{6+}+\mathrm{W}_{j}^{5+} .
$$

More specifically, the electrons are believed to enter localized states positioned $0.1-0.2 \mathrm{eV}$ below the conduction band. The atoms are displaced so that a potential well is formed, and pronounced electron-phonon interaction leads to the formation of polarons with an extent of 0.5-0.6 nm [86]. More detailed descriptions can be found in recent work [102], and the effect of $\mathrm{W}^{4+}$ has sometimes been emphasized [114,115]. Polaron-induced optical absorption in W oxide produces a broad band centered at $\lambda \approx 0.85 \mu \mathrm{m}$ and extending into the luminous part of the spectrum so that thin films attain a blue color in transmission. The spectral dependence of the absorption can be described in detail by theory $[103,116,117]$. 


\subsection{Comments on mixed oxides}

Mixed oxides can sometimes have better EC properties than pure oxides, one reason being that additional optical transitions are possible and can produce an intermixing of polaron-induced absorption bands. Much work has been devoted recently on oxides based on W-Ti, W-V, W-Ni, W-Nb, W-Mo, W-Ta, Mo-Ti, Mo-V, Mo-Nb, Mo-Ce, Ti-V, Ti-Zr, Ir-Sn, Ir-Ta, Ni-Al, Ni-Ti, Ni-V, and many others [31]. Complexation between $\mathrm{WO}_{3}$ and an organic substance is another option [118]. Recent studies have been reported on W-Ti oxide [119] and Ni-Ir oxide [120,121], for which a minor amount of Ti or Ir produced strongly enhanced electrochemical durability.

Further optimization of EC oxides can be accomplished in ternary compositions, and a comprehensive study was recently performed on thin films of $\mathrm{W}_{1-x-y} \mathrm{Ti}_{x} \mathrm{Mo}_{y} \mathrm{O}_{3}$ with $x<0.2$ and $y<0.2$ [122]. The well-established ability of $\mathrm{Ti}$ addition to give electrochemical durability for $\mathrm{WO}_{3}[119,123,124]$ could be combined with the also well-known capability of Mo addition to provide color neutrality to $\mathrm{WO}_{3}$ [125-127]. Fig. 4 shows chromaticity coordinates for several oxides with $\mathrm{Ti}$ contents of $\sim 10$ at.\% and demonstrates that approximate color neutrality can be obtained [122]. Electrochemical durability was impeded at excessive Mo contents, and it was appropriate to maintain the amount of Mo below $\sim 6$ at.\%. Complex oxides of anodically coloring EC oxides have been investigated recently too, and interesting results have been reported for oxides of $\mathrm{Ni}-\mathrm{W}-\mathrm{Li}$ [128], Ni-Al-Li [129], Ni$\mathrm{Zr}-\mathrm{Li}$ [130], Ni-Fe-C [131] and Ni-Ti-Li [132] as well as on Ni-LiPON [133]. 


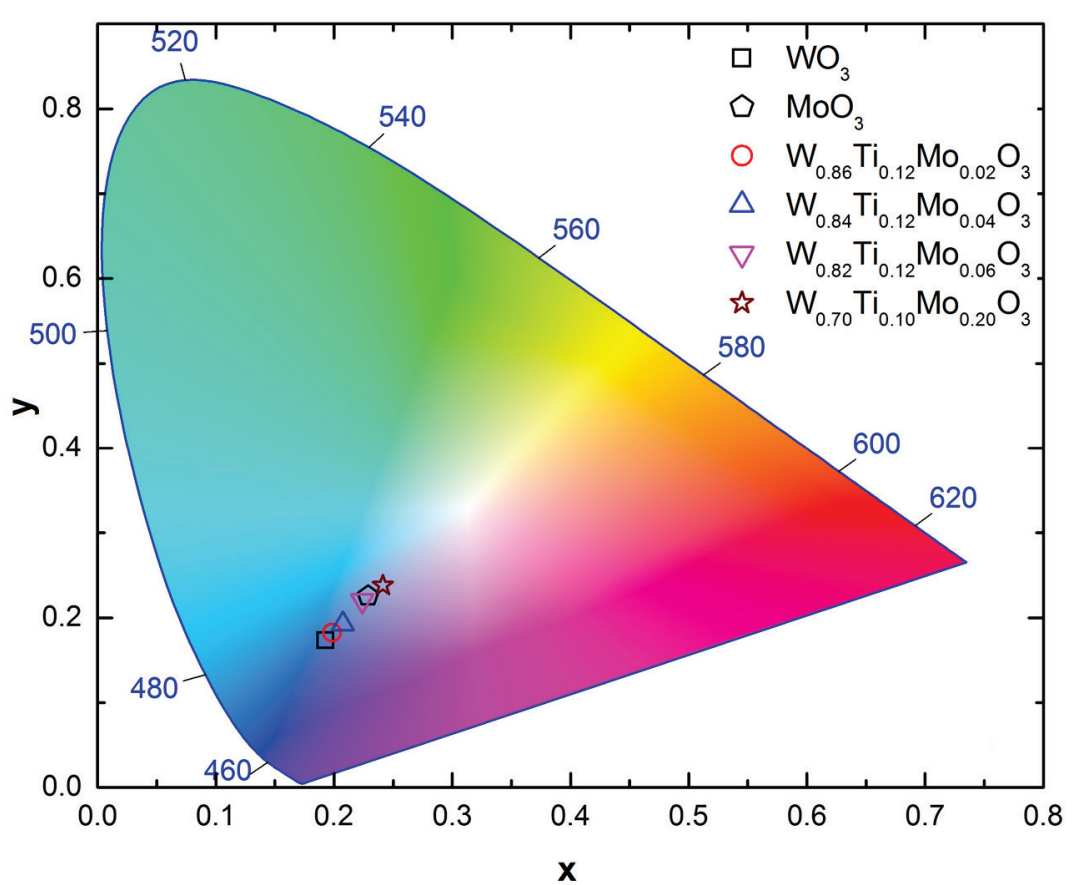

Fig. 4. CIE 1931 chromaticity diagram with $(\mathbf{x}, \mathbf{y})$ coordinates for $\sim 300$-nm-thick $\mathrm{W}_{1-x-y} \mathrm{Ti}_{x} \mathrm{Mo}_{y} \mathrm{O}_{3}$ films with the shown compositions. Numbers along the curve denote wavelengths in $\mathrm{nm}$. From Arvizu et al. [122].

\section{Case study: flexible EC foil}

Several variations are possible for the generic EC design reported in Sec. 2.1, and the present section presents data for one of these, specifically for a mechanically flexible foil which can be produced by low-cost high-productivity roll-to-roll processing. The design is illustrated in Fig. 5 and comprises (i) a 0.175-mm-thick PET foil with a transparent electrically conducting $\mathrm{In}_{2} \mathrm{O}_{3}: \mathrm{Sn}$ film and a film of EC W oxide, (ii) another PET foil with a transparent electrically conducting $\operatorname{In}_{2} \mathrm{O}_{3}: \mathrm{Sn}$ film and a film of EC Ni oxide, and (iii) a polymer electrolyte joining the two EC oxides. The foil can be used in different ways: it can be fixed onto the surface of an existing glass pane, it can be suspended between two glass panes in glazing thus effectively altering it from a double-glazed to a triple-glazed construction without significantly increasing the weight, and it can be used for glass lamination as delineated in the left-hand part of Fig. 5. Some of these constructions can give added functionalities to the EC device and impart spall shielding, burglar protection, etc. 


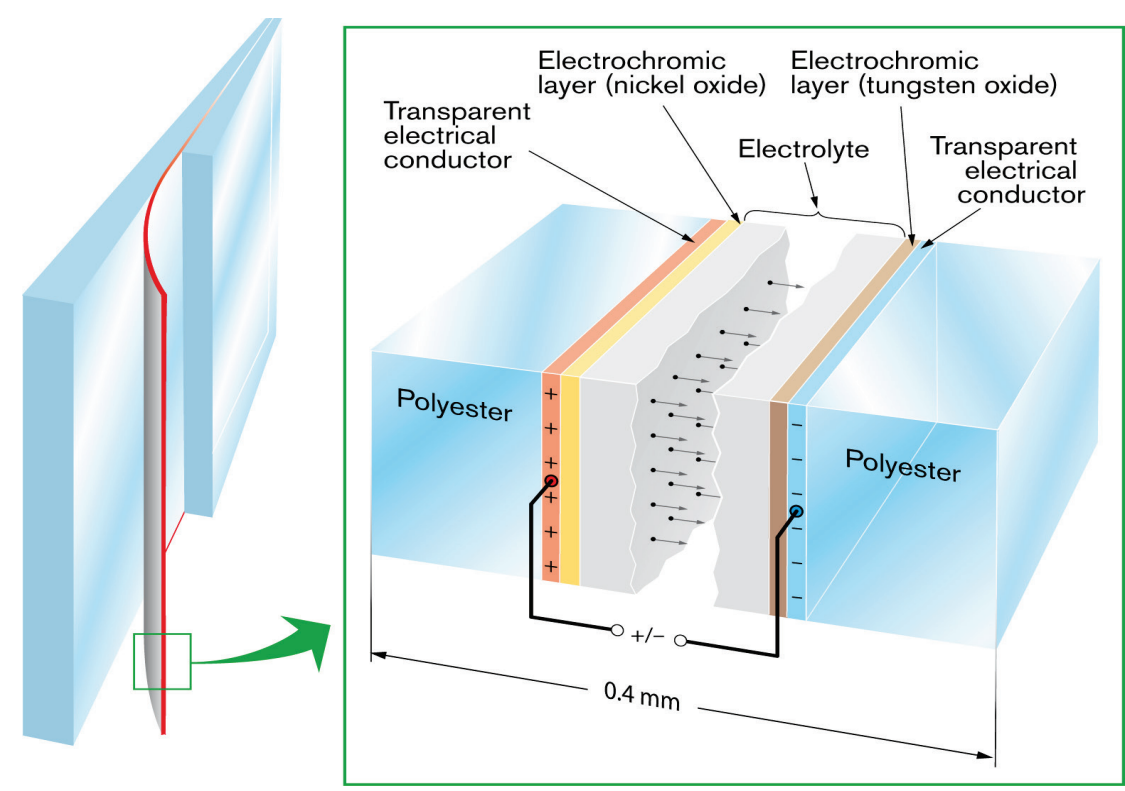

Fig. 5. Principle design of a foil-based EC device (cf. Fig. 2). Arrows indicate ion transport when a voltage is applied between the transparent electrical conductors. The entire foil can be employed to laminate glass panes, as shown in the left-hand part.

Fig. 6 gives some background for understanding the optical properties of an EC foil [134]. Upper panel shows $T(\lambda)$ in the luminous spectral range after charge exchange to the stated levels and demonstrates that the transmittance can be modulated within a wide range. The middle and lower panels in Fig. 6 illustrate the optical modulation of the individual Woxide-based and Ni-oxide-based components after the device has been disassembled. Clearly the oxide films are optically complementary with the W-oxide-based film showing cathodic coloration mainly in the long-wavelength part of the luminous spectrum while the Ni-oxidebased film displays anodic coloration mainly at short wavelengths.

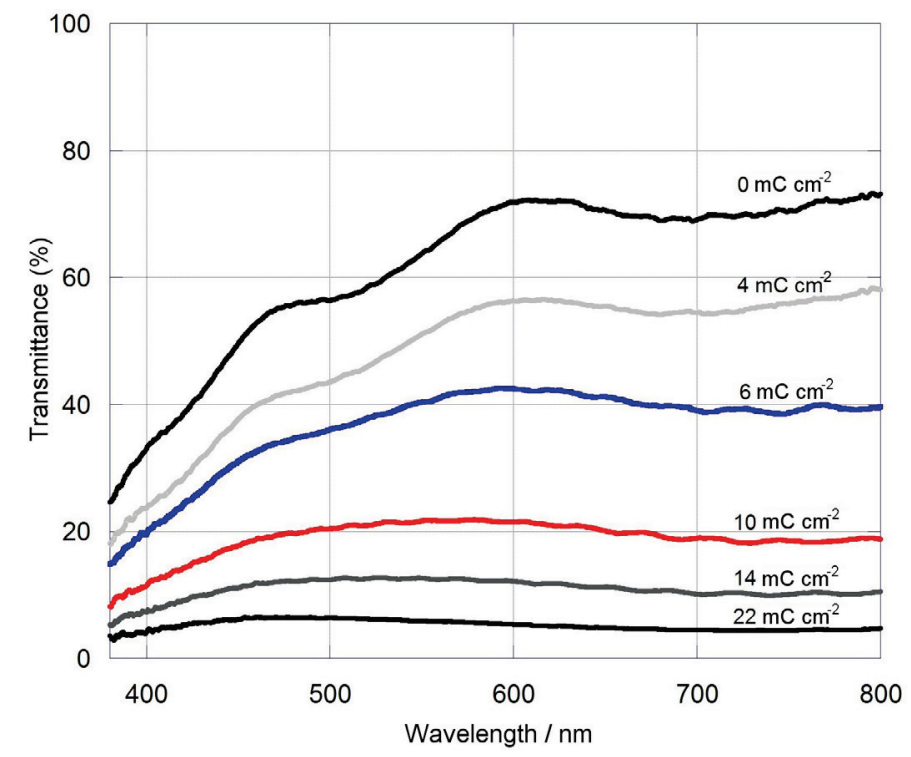



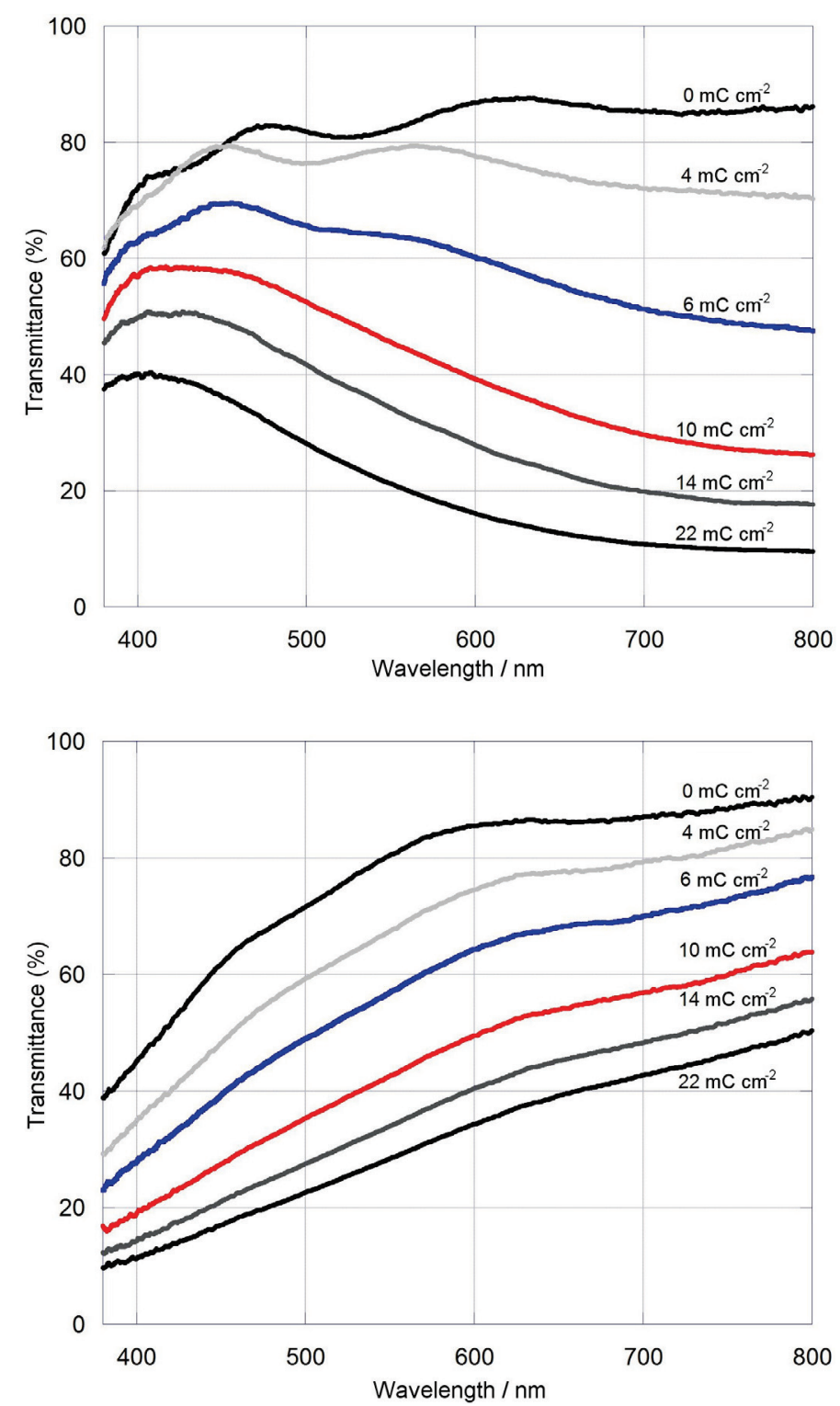

Fig. 6. Spectral transmittance for an as-prepared EC foil device of the kind shown in Fig. 5 (upper panel), and similar data for the W-oxide-based (middle panel) and Ni-oxide-based (bottom panel) parts of the device. From Granqvist et al. [134].

Fig. 7 shows optical modulation under extended coloration and bleaching of a $240-\mathrm{cm}^{2}-$ size EC foil device [134]. Upper panel demonstrates mid-luminous $(\lambda=0.55 \mu \mathrm{m})$ transmittance for two consecutive cycles adjusted to give a transmittance modulation $\Delta T$ of $55 \%$. Half of the transmittance range (from point 1 to 2 ) took $\sim 10 \mathrm{~s}, 90 \%$ of this interval (from point 1 to 3 ) took $\sim 20 \mathrm{~s}$, while the full range (from point 1 to 4 ) took $\sim 30 \mathrm{~s}$. Slower cycling could yield a larger value of $\Delta T$. Lower panel of Fig. 7 shows evolution of maximum and minimum transmittance during the initial color-bleach cycles. The optical modulation range remained almost unchanged for thousands of cycles. 

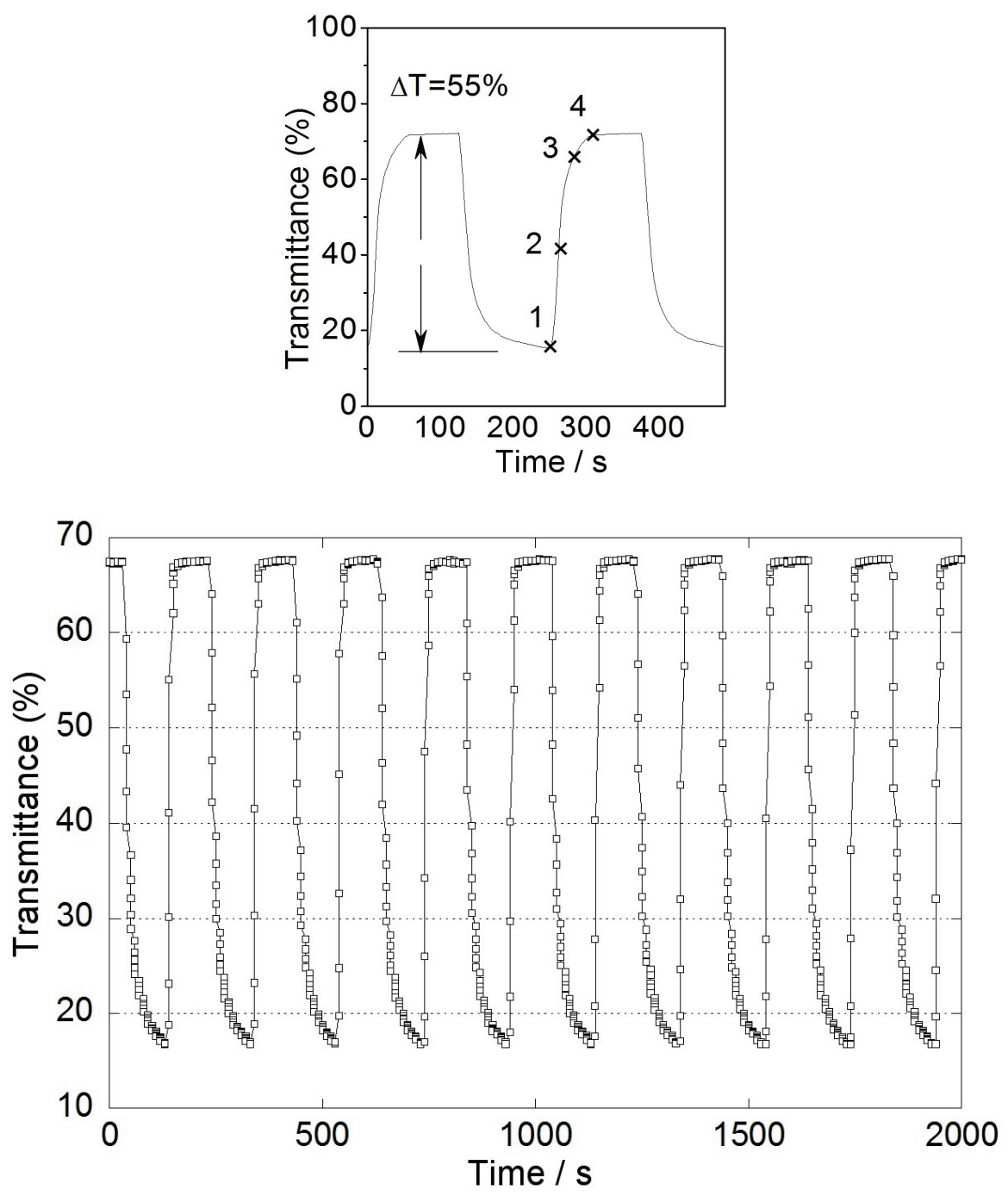

Fig. 7. Mid-luminous transmittance for an EC foil device of the kind shown in Fig. 5 adjusted to give a transmittance modulation $\Delta T$ of $55 \%$. Upper panel shows transmittance for two consecutive colorbleach cycles (numbers 1-4 are used in the main text) and lower panel shows evolution of maximum and minimum transmittance during several color-bleach cycles. From Granqvist et al. [134].

EC foils for glazing are prone to be exposed to ultraviolet irradiation, which can give a photochromic effect in addition to the electrochromism [135,136]. If so desired, photochromism can be avoided by over-coating the $\mathrm{W}$ oxide film with $\mathrm{Ta}_{2} \mathrm{O}_{5}$ [137] Photochromism has been noted also in Ni-oxide based films [138].

Color-bleach dynamics can be an important property for EC devices. For small devices, the time for going from dark to fully transparent states, or vice versa, can be as little as a few seconds, but large devices are slower since greater quantities of electrical charge must be inserted or extracted through electrical contacts (known as "bus bars") at one or, preferably, several of the devices' edges. EC devices can show an "iris effect" with the color change 
being faster at the edge than in the center, but this often unwanted feature may be compensated via the electrical drive circuitry.

The preferred range of optical modulation depends on the intended application of the EC foil. In buildings, it is often desirable to have glazing with large bleached-state transmittance, and antireflection coatings can then be used provided they do display excessive light scattering ("haze") $[136,139]$. If instead glare control is most important, it is feasible to decrease the colored-state transmittance radically through superimposed foils. Thus if the transmittance is $10 \%$ in the dark state for an EC foil, then two superimposed foils give a transmittance of only $\sim 1 \%$. Long-term durability is another essential parameter, which is discussed in more detail in Sec. 4.

Foil-type EC devices include a layer of a polymer electrolyte, which can be functionalized by nanoparticles. Most research on this aspect of EC devices used a "model electrolyte" of polyethyleneimine-lithium bis(trifluoromethylsulfonyl) (PEI-LiTFSI) [140,141], but similar functionalization can be implemented for the electrolyte of the EC foil device in Fig. 5 [142]. One interesting option is based on nanoparticles of a transparent electrical conductor such as $\operatorname{In}_{2} \mathrm{O}_{3}: \mathrm{Sn}$, in which case it is possible to achieve near-infrared plasmon-based absorption and diminish $T_{\text {sol }}$ without appreciably affecting $T_{\text {lum }}$ [141]. This property is important for EC glazing particularly in warm climates. Fig. 8 shows $T(\lambda)$ and proves that strong near-infrared absorption occurs when the amount of nanoparticles is increased. Using 7 wt. $\%$ of $\operatorname{In}_{2} \mathrm{O}_{3}: \mathrm{Sn}$, the EC foil has $T_{\text {lum }}=83.3 \%$ and $T_{\text {sol }}=56.3 \%$, while the electrolyte stays essentially free from haze. The measured data on $T(\lambda)$ can be reconciled with quantitative calculations, as shown by the symbols in Fig. 8, which follows from the detailed theoretical understanding of the properties of $\operatorname{~n}_{2} \mathrm{O}_{3}: \mathrm{Sn}$ [143] and of accurate descriptions (“effective-medium models") for the optical properties of not too concentrated suspensions of nanoparticles [144]. 


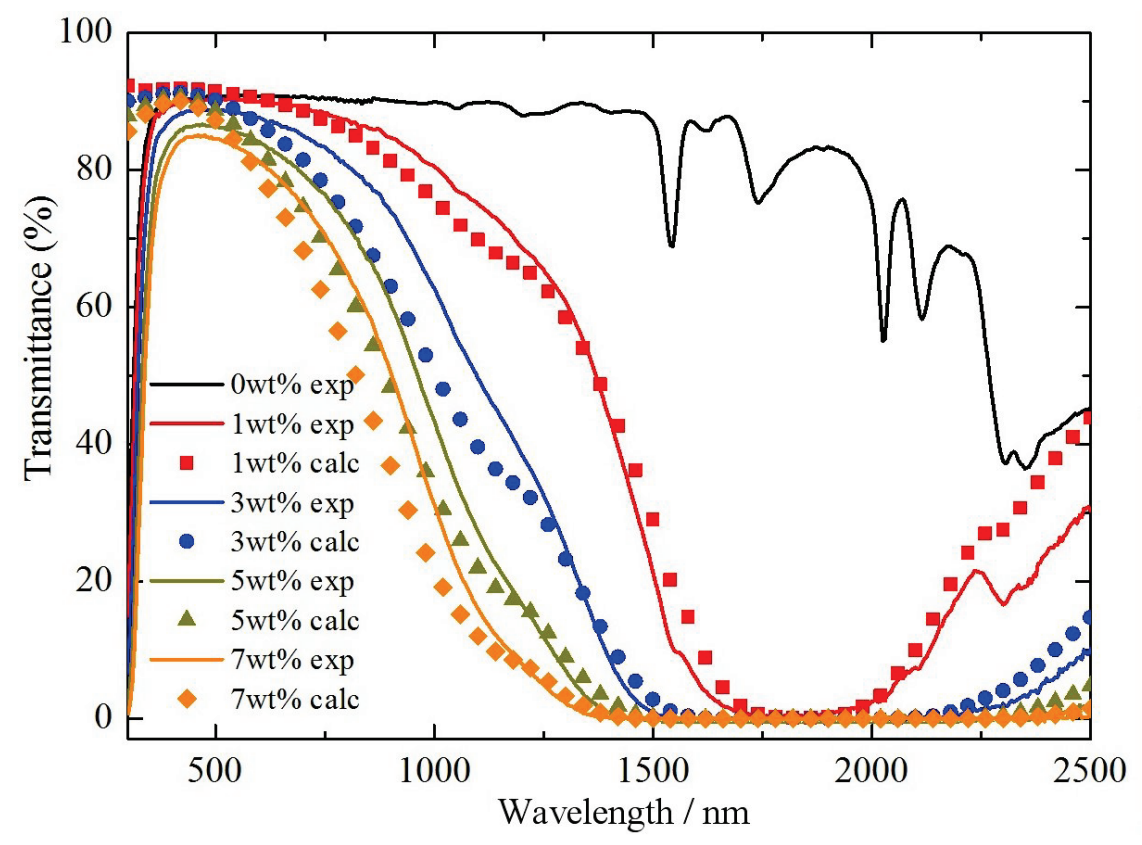

Fig. 8. Spectral transmittance vs. the amount of of $\operatorname{In}_{2} \mathrm{O}_{3}: \mathrm{Sn}$ nanoparticles in electrolytes of (PEI$\mathrm{In}_{2} \mathrm{O}_{3}: \mathrm{Sn}$ ):LiTFSI. Experimental data (curves) and calculations (symbols) are shown. From Bayrak Pehlivan et al. [141].

The EC foil in Fig. 5 can be produced by roll-to-roll web coating [71,145], which is well known to be a technology combining low cost with high productivity [146,147], and this thinfilm deposition process can be combined with continuous lamination of $\mathrm{W}$-oxide-coated and Ni-oxide-coated PET foils by use of the polymer electrolyte. The end products are then large flexible sheets for glass lamination, which can be cut to any size and shape after which "bus bars" are applied. Consequently, manufacturing of the final foil-based device-for example an EC-based glazing - can be removed from the site for foil production.

Fig. 9 shows installations of full-size glazing with EC-based foil laminated between large glass panes. Two of the windows in the upper panel are dark and look distinctly different from the adjacent clear window. The time for going from fully dark to fully colored states is of the order of ten minutes, which is appropriate for allowing the eye to light-adapt. No visible haze or other imperfections were noted. The lower panel of Fig. 9 depicts a commercial building with foil-based EC glazing on the lower two floors. 

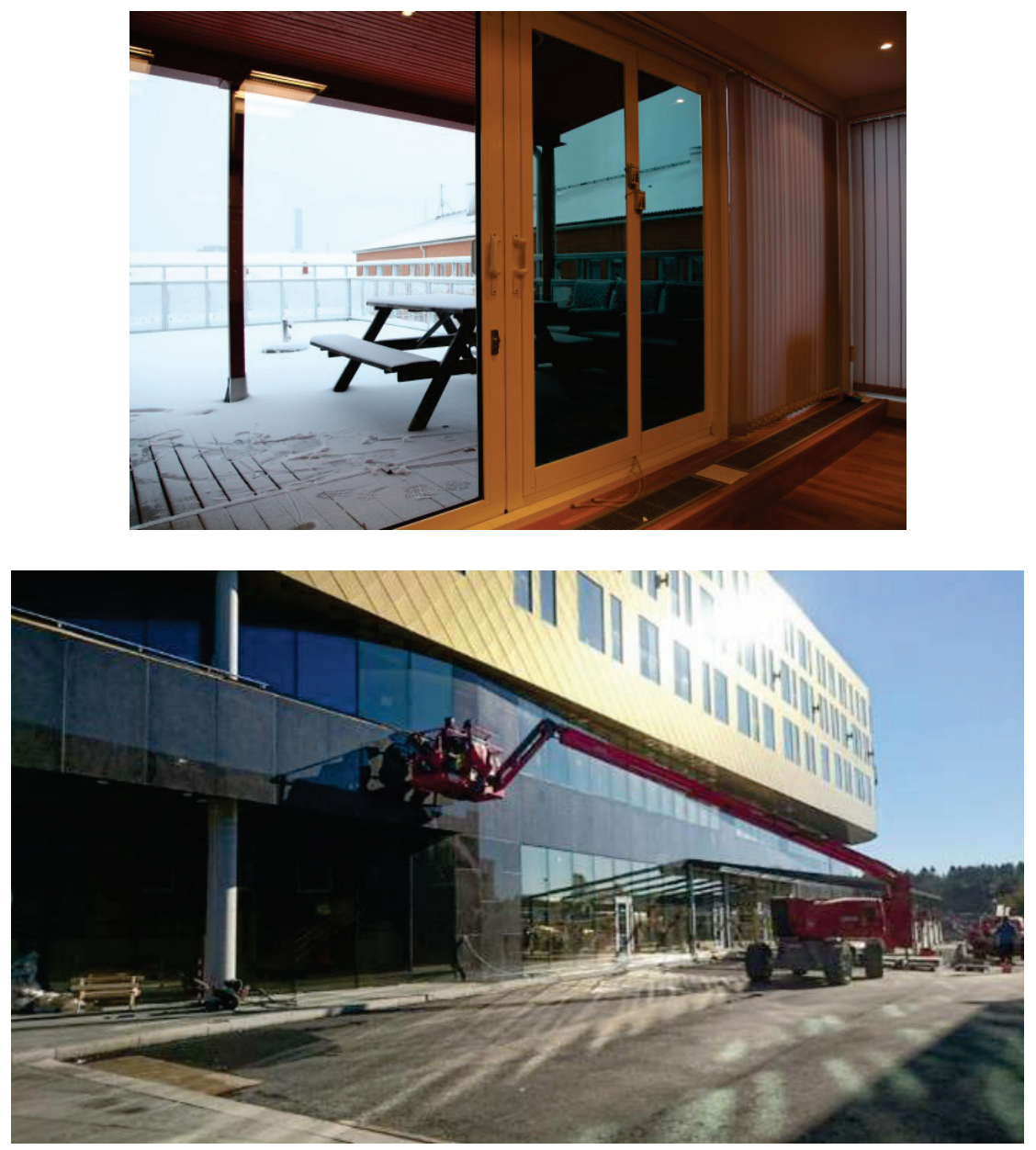

Fig. 9. Examples of interior (upper panel) and exterior (lower panel) views of EC glazing based on web-coated foils.

\section{Towards superior EC glazing}

\subsection{Long-term durability assessment of EC films}

Long-term durability is an obvious requirement for most EC devices, and this property has been investigated repeatedly [1,148-153]. Durability is multi-faceted and includes the ability to maintain charge transport between the two thin films in an EC device for many thousands of cycles without major loss of performance, resistance against degradation by solar irradiation for extended times, chemical ruggedness especially with regard to interfaces, sufficient shelf-life, etc.

Recent work studied the decrease in the charge density $Q$-and therefore of the coloration — for films of EC Ni oxide [154,155] and W oxide [156]. Fig. 10 shows data recorded under electrochemical cycling for up to $10^{4}$ cycles. Panel (a) reports current density as the voltage applied to the films was swept between set endpoints and demonstrates cycledependent differences. The encircled areas correspond to charge density exchange, whose 
evolution is given in Fig. 10(b); it can be represented as an almost linear drop when the number of cycles $x$ as well as $Q$ are expressed on logarithmic scales.
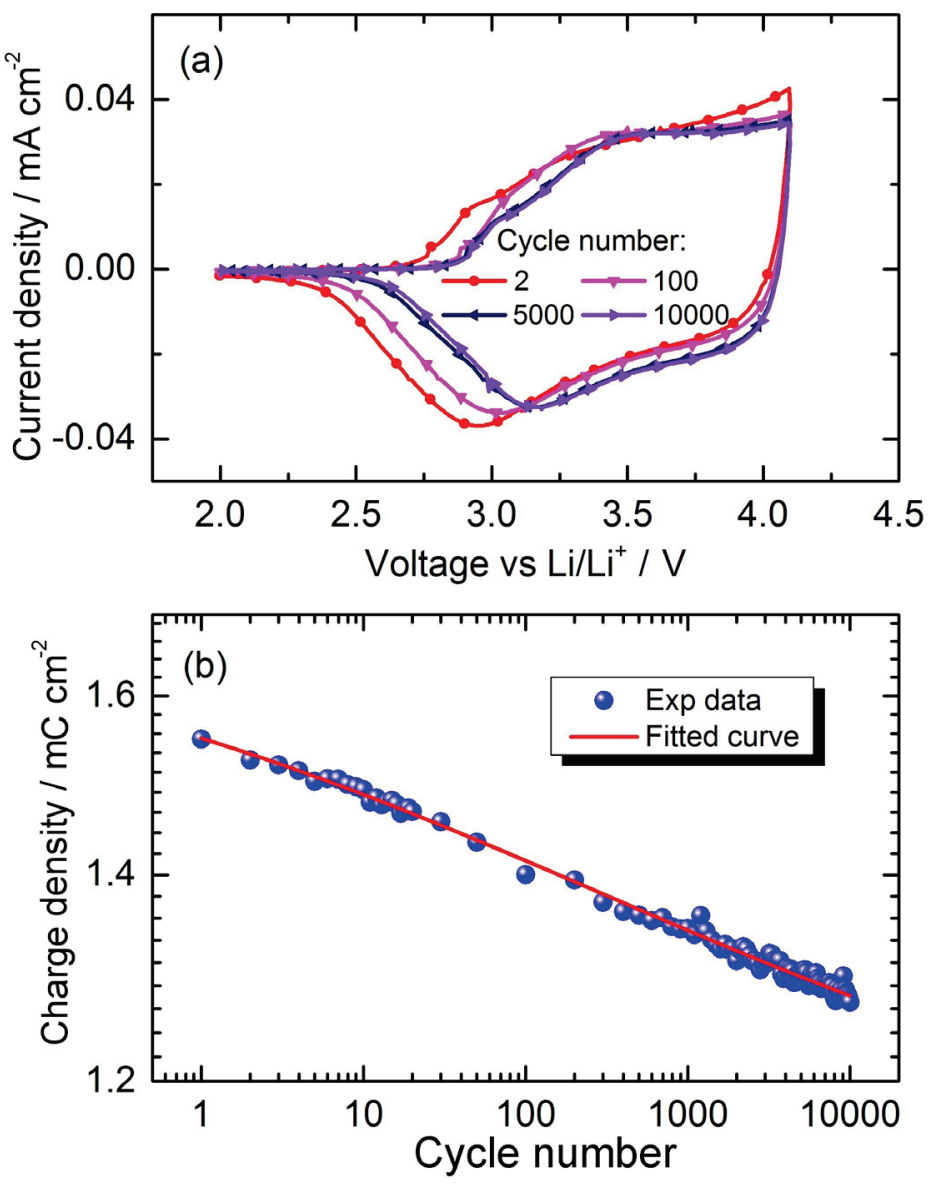

Fig. 10. Current density vs. voltage during long-time electrochemical cycling (a) and associated charge density exchange (b) for a Ni-oxide-based EC film immersed in a Li-ion-conducting electrolyte. Dots in panel (b) show experimental data and the curve was drawn as a fit to Eq. (5). Panel (b) is reproduced from Wen et al. [154].

Several functional dependencies were implemented to fit the data in Fig. 10(b), and it was found that a power-law or, alternatively, a stretched-exponential expression could accurately represent the decline of the charge density [155]. Specifically the fittings used the expression

$$
Q=A_{2}+\frac{A_{1}-A_{2}}{1+\left(\frac{x}{x_{0}}\right)^{p}}
$$

for the power law, where $A_{1}$ and $A_{2}$ are the initial and final charge capacities, $x_{0}$ is the cycle number at which the charge density has declined to the average of its initial and final value, and $p$ is a kinetic exponent. The fitting parameters depended on film composition and voltage range for ion insertion/extraction. The underlying model for degradation may be connected 
with dispersive chemical kinetics [157] and involve a variety of diffusion-limited reactions that still are poorly understood.

\subsection{Rejuvenation of degraded EC films}

Another recent discovery demonstrated unambiguously that degraded EC films could be rejuvenated so that they recover their original properties [80]. This may open new ways for long-term use of EC devices, and the finding may also be relevant for other ionics-based devices such as electrical batteries. Most studies of rejuvenation have so far been carried out on W oxide and have encompassed galvanostatic [80] as well as potentiostatic [81] treatment. Rejuvenation can be performed many times [158] and has been demonstrated also for other EC materials such as Ti oxide [159] and Mo oxide [160]. Fig. 11 shows data from a study of sputter deposited $\mathrm{WO}_{3}$ thin films immersed in a Li-conducting electrolyte and serves as a clear demonstration of rejuvenation. Panel (a) shows data on electrochemical cycling of a film after the initial and the $400^{\text {th }}$ cycle in the stated voltage interval. There is an apparent drop of the charge density exchange, and Fig. 10(c) demonstrates a corresponding decrease of the optical modulation.
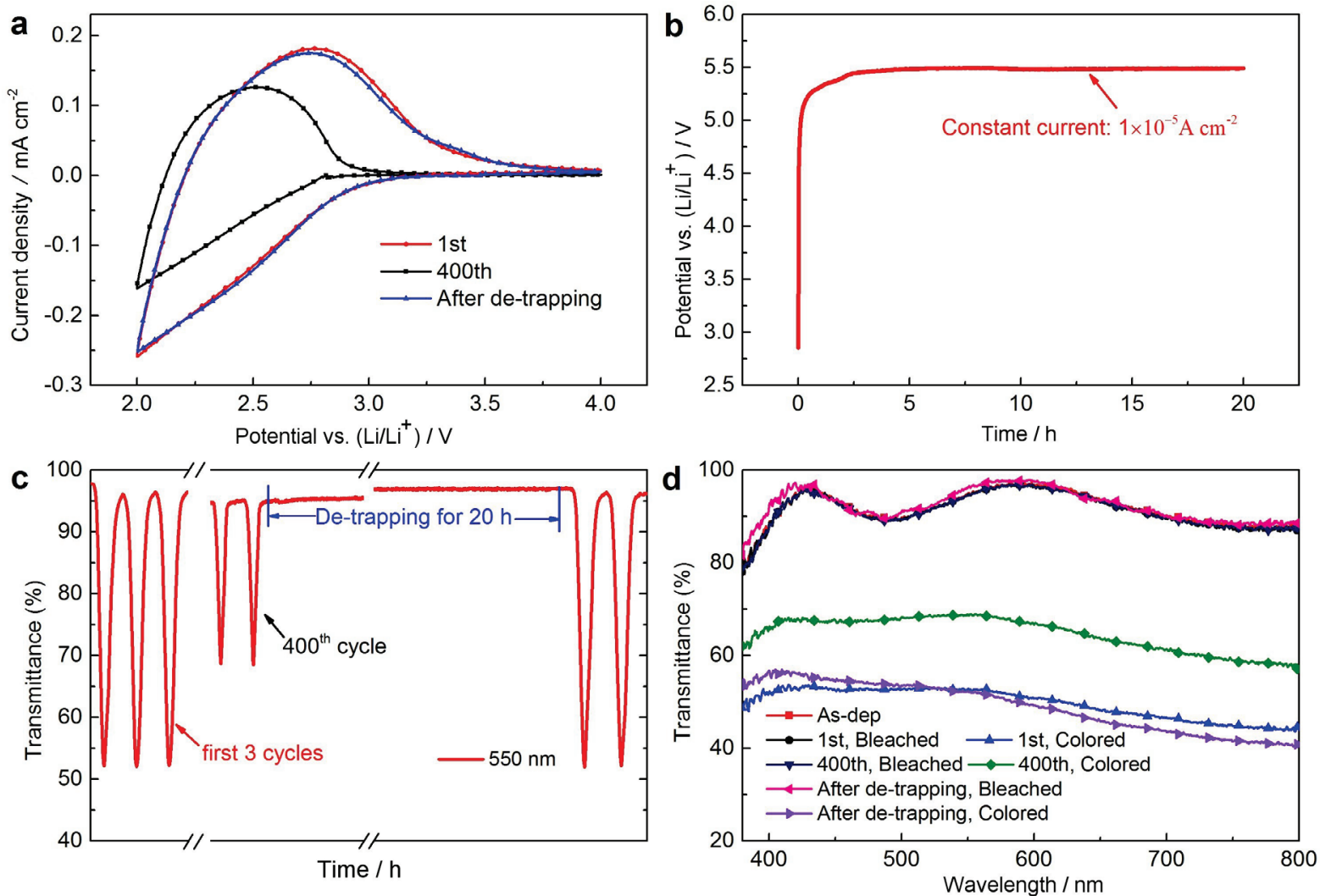
Fig. 11. Galvanostatic rejuvenation of an EC W oxide film, showing electrochemical cycling data performed in a Li-conducting electrolyte (a), open-circuit voltage during galvanostatic expulsion of trapped ions (b), mid-luminous optical transmittance (c) and in the entire luminous wavelength range (d). Spectral transmittance data overlap partly for bleached films. From Wen et al. [80].

Device degradation can be assigned to trapping of Li ions by following notions assuming that $\mathrm{W}$ oxide can be represented as a network of connected sites with low inter-site barriers, and allowing fast ion diffusion throughout the host material, and other sites with higher energy barriers which are capable of trapping diffusing ions [161-164]. The trapping hypothesis was probed by applying a constant current density of $10^{-5} \mathrm{~A} \mathrm{~cm}^{-2}$ through a W oxide film for $20 \mathrm{~h}$ in the "bleaching direction". The potential then grew from $\sim 2.8$ to $\sim 5.5 \mathrm{~V}$, as apparent from Fig. 11(b), while the optical transmittance remained high and virtually unchanged. Subsequent to this galvanostatic treatment, the open-circuit potential returned to its initial value of $\sim 3.3 \mathrm{~V}$, thus indicating that the original properties were recovered. Optical transmittance provided further proof that the film was indeed rejuvenated, which is clear from the information in Fig. 11(c) and also for data on $T(\lambda)$ in Fig. 11(d). Furthermore, the electrochemical cycling data returned to those for the pristine film, as indicated in Fig. 11(a). Potentiostatic rejuvenation revealed some additional features, and a conspicuous peak in the current density was associated with a rapid change in the optical transmittance [81].

The above results suggest strongly that Li ion de-trapping is possible, and conclusive evidence on this matter was obtained by analyzing the Li content-including its depth profile - by time-of-flight elastic recoil detection analysis (ToF-ERDA) [165] and time-offlight secondary ion mass spectroscopy (ToF-SIMS) [166]. Fig. 12 shows that the optical transmittance modulation is rapidly diminished during electrochemical cycling until it reaches the point denoted II at which the Li content was investigated and found to be much greater than in the pristine film. Galvanostatic rejuvenation according to the procedures delineated above led to abrupt onset of high transmittance after $\sim 9 \mathrm{~h}$, which could be correlated with detrapping of $\mathrm{Li}$ ions as evident from the absence of $\mathrm{Li}$ in the ToF-ERDA data corresponding to point III in Fig. 12. 


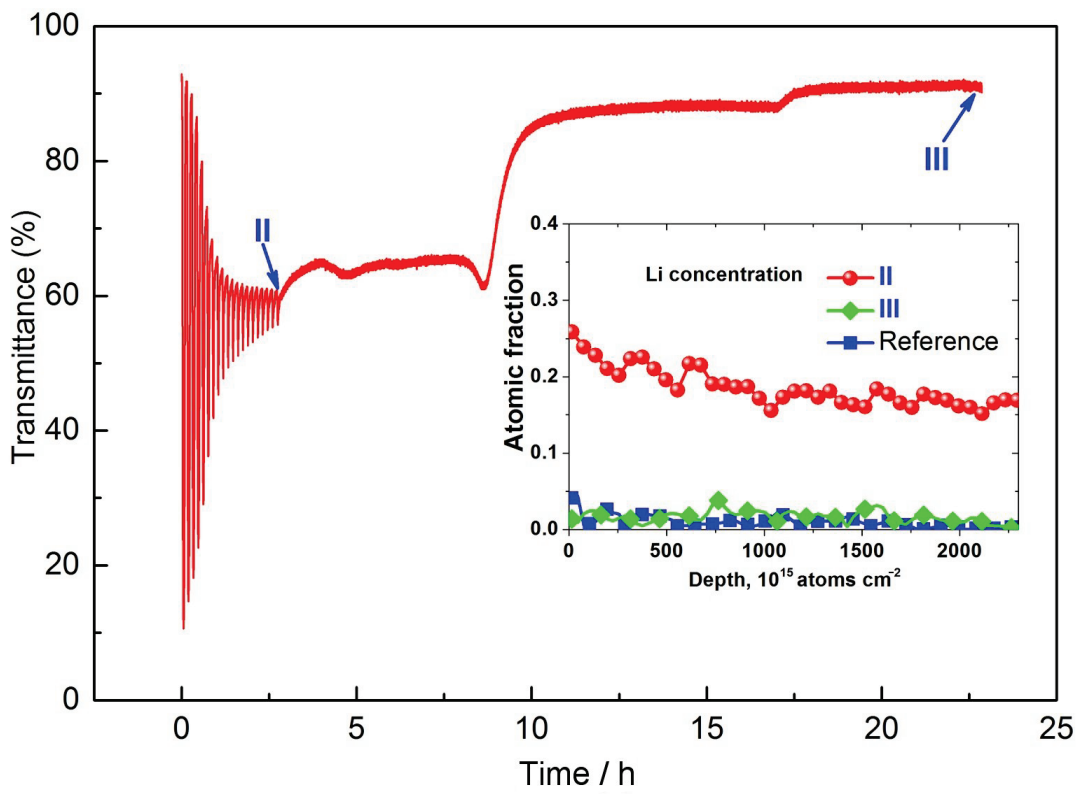

Fig. 12. Mid-luminous optical transmittance vs. time during galvanostatic rejuvenation of a $\mathrm{W}$ oxide film. Inset shows ToF-ERDA depth profiles for Li ions corresponding to points II and III as well as for a reference sample that only had been immersed in the electrolyte. From Arvizu et al. [165].

Very recent results show that electrochemical rejuvenation can be accomplished also in anodically coloring EC Ni oxide films immersed in an electrolyte of $\mathrm{LiClO}_{4}$ in propylene carbonate, and that ion accumulation and ion release again takes place and, interestingly, involves $\mathrm{Li}$ as well as $\mathrm{Cl}$ [167]. Fig. 13 reports some characteristic transmittance data and shows that the optical modulation drops during 500 electrochemical cycles (corresponding to $11 \mathrm{~h}$ of treatment). Potentiostatic rejuvenation was then applied during a period of $20 \mathrm{~h}$, during which the transmittance reached a low level, and this treatment was followed by a resting period of $2 \mathrm{~h}$. Finally, the data in the right-hand part of Fig. 13 indicate that the initial optical performance was regained, at least approximately. The new results for Ni oxide show that both the cathodic and anodic components of a typical EC device can be rejuvenated, but work is still needed to demonstrate rejuvenation of a complete device. It should be emphasized that the physics and chemistry for the rejuvenation processes still are not well understood. 


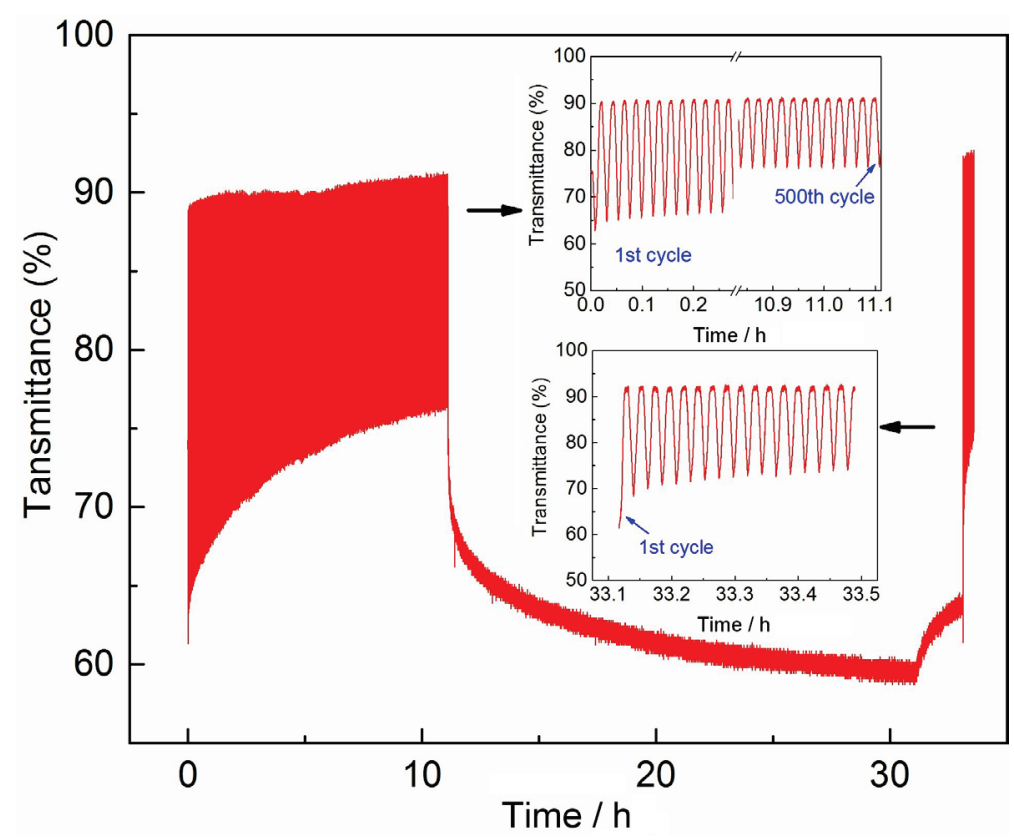

Fig. 13. Mid-luminous optical transmittance vs. time of an EC $\mathrm{Ni}$ oxide film subjected to electrochemical cycling and degradation, potentiostatic rejuvenation followed by a brief resting period, and resumed electrochemical cycling. Selected time-resolved data are shown in the insets.

\section{Some conclusions and perspectives}

EC glazing has progressed dramatically since its feeble beginnings in 1984 [45,46]. Such glazing is presently (2017) manufactured by at least four companies and is installed in buildings, especially in Europe and the USA, where it yields energy efficiency along with indoor comfort and other amenities. Low-cost manufacturing and long-term durability are keys to successful products and, as discussed in this article, web-coating can be implemented to create light-weight, rugged EC devices in the form of large sheets or on a roll suitable for glass lamination and incorporation in glazing. Reactive DC magnetron sputtering appears to be a preferred deposition technology, but other options, for example based on sol-gel deposition [168] or inkjet printing [169], may be used. In contrast with many other "green" technologies, electrochromism does not rely on "critical" rare-earth elements with questionable availability [170]. The electrolyte in the EC device can be based on an ecofriendly biohybrid $[171,172]$, which strengthens the notion that electrochromic technology is environmentally benign.

Predictions about future developments are notoriously difficult, but here follow some perspectives on multifunctionality in conjunction with electrochromics, which may become a key issue [173,174]. Thus it is possible to combine energy generation [175,176], energy storage [177-181], or light-emission [182] with electrochromism, and another aspect of 
multifunctionality regards "dual-band" EC devices that are capable of separately modulating luminous radiation and near-infrared solar radiation [54,183-187]. Still another possibleperhaps even likely-future development of EC technology concerns thermochromic (temperature-dependent) control of solar energy throughput, which can be added to electrochromism via $\mathrm{VO}_{2}$-based nanoparticles [188-190] in the electrolyte in analogy with the application of nanoparticles discussed in Sec. 3 above [191]. Furthermore, it is feasible to invoke photocatalytic remediation of indoor air [192,193] in conjunction with EC glazing; the temperature increase caused by optical absorption in a darkened EC device can contribute significantly to the efficiency of the air purification.

The discussion in this paper was centered on glass-based products, but this is not the only option for web-coated EC devices, which may be employed in membrane architecture of a kind that already is well-established in sports stadiums, function halls, etc. [194,195]. The membranes are based on transparent or translucent ethylene tetrafluoroethylene (ETFE), which has proven durability for many decades even under full solar irradiation. Coating ETFE with a transparent electrical conductor is a critical step, but recent advances in thin-film deposition [196] and sub-second heat treatment of thin films on polymer substrates $[197,198]$ strongly indicate that the technical challenges can be met. Flexible web-coated EC membranes therefore stand out as an interesting possibility for future innovative architecture.

Acknowledgement: H.-Y. Qu is grateful for financial support from the China Scholarship Council Doctoral Joint-Training Program.

\section{References}

[1] C.G. Granqvist, Handbook of Inorganic Electrochromic Materials, Elsevier, Amsterdam, The Netherlands, 1995.

[2] R.J. Mortimer, D.R. Rosseinsky, P.M.S. Monk, P.M.S., editors, Electrochromic Materials and Devices, Wiley-VCH, Weinheim, Germany, 2015.

[3] M.R. Raupach, Pinning down the land carbon sink, Nat. Climate Change 1 (2011) 148-149.

[4] U.S. Department of Commerce, National Oceanic and Atmospheric Administration, Earthscan System Research Laboratory, Global Monitoring Division; http://www.esrl. noaa.gov/gmd/ccgg/trends/index. html. Accessed 24 March 2017.

[5] T.F. Stocker, D. Qin, G.-K. Plattner, M.M.B. Tignor, S.K. Allen, J. Boschung, A. Nauels, Y. Xia, V. Bex, P.M. Midgley, editors, Climate Change 2013: The Physical Science Basis. Contribution of Working Group I to the Fifth Assessment Report of the Intergovermental Panel on Climate Change, 
Cambridge University Press, New York, NY, USA 2013.

[6] J. Scheffran, M. Brzoska, J. Kominek, P.M. Link, J. Schilling, editors, Climate Change, Human Security and Violent Conflict: Challenges for Social Stability, Springer, Berlin, Germany, 2012.

[7] M. Burke, S.M. Hsiang, E. Miguel, Global non-linear effect of temperature on economic production, Nature 527 (2015) 235-239.

[8] T.K.R. Matthews, R.L. Wilby, C. Murphy, Communicating the deadly consequences of global warming for human heat stress, Proc. Nat. Acad. Sci. USA 114 (2017) 3861-3866.

[9] T. Wheeler, J. von Braun, Climate change impacts global food security, Science 341 (2013) 508513.

[10] S.A. Henson, C. Beaulieu, T. Ilyina, J.G. John, M. Long, R. Séférian, J. Tjiputra, J.L. Sarmiento, Rapid emergence of climate change in environmental drivers of marine ecosystems, Nat. Commun. 8 (2017) 14682/1-14682/9.

[11] C. Schädel, M.K.-F. Bader, E.A.G. Schuur, C. Biasi, R. Bracho, P. Čapek, S. De Baets, K. Diáková, J. Ernakovic, C. Estop-Aragones, D.E. Graham, I.P. Hartley, C.M. Iversen, E. Kane, C. Knoblauch, M. Lupascu, P.J. Martikainen, S.M. Natali, R.J. Norby, J.A. O'Donnell, T.R. Chowdhury, K. Šantrůčková, G. Shaver, V.L. Sloan, C.C. Treat, M.R. Turetsky, M.P. Waldrop, K.P. Wickland, Potential carbon emissions dominated by carbon dioxide from thawed permafrost soils, Nat. Climate Change 6 (2016) 950-953.

[12] United Nations Department of Economic and Social Affairs, World Population Prospects: The 2015 Revision, United Nations, New York, NY, USA, 2015.

[13] H. Akbari, C. Cartalis, D. Kolokotsa, A. Muscio, A.L. Pisello, F. Rossi, M. Santamouris, A. Synnefa, N.H. Wong, M. Zinzi, Local climate change and urban heat island mitigation techniques: the state of the art. J. Civil Engr. Mgm. 22(1) (2016) 1-16.

[14] United Nations Environmental Programme, Buildings and Climate Change: Summary for Decision-Makers, UNDP Sustainable Buildings \& Climate Initiative, Paris, France, 2009.

[15] U.S. Department of Energy, 2011 Buildings Energy Data Book, Washington, DC, USA, 2012.

[16] B. Richter, D. Goldston, G. Crabtree, L. Glicksman, D. Goldstein, D. Greene, D. Kammen, M. Levine, M. Lubell, M. Savitz, D. Sperling, F. Schlachter, J. Scofield, J. Dawson, How America can look within to achieve energy security and reduce global warming, Rev. Mod. Phys. 80 (2008) S1S107.

[17] http://ec.europa.eu/energy/en/topics/energy-efficiency. Accessed on 26 April 2017.

[18] G.B. Smith, C.G. Granqvist, Green Nanotechnology: Solutions for Sustainability and Energy in the Built Environment, CRC Press, Boca Raton, FL, USA, 2010.

[19] D.S. Ginley, D. Cahen, D., editors, Fundamentals of Materials for Energy and Environmental Sustainability, Cambridge University Press, Cambridge, UK, 2012.

[20] J. García-Martínez, J., editor, Nanotechnology for the Energy Challenge, second edition, WileyVCH, Weinheim, Germany, 2013.

[21] F. Pacheco-Torgal, M.V. Diamanti, A. Nazari, C.G. Granqvist, editors, Nanotechnology in EcoEfficient Construction, Woodhead, Cambridge, UK, 2013. 
[22] F. Pacheco-Torgal, M. Mistretta, A. Kauklauskas, C.G. Granqvist, L.F. Cabeza L.F., editors, Nearly Zero Energy Building Refurbishment, Springer, London, UK, 2013.

[23] F. Pacheco-Torgal, J.A. Labrincha, L.F. Cabeza, C.G. Granqvist, editors, Eco-Efficient Materials for Mitigating Building Cooling Needs: Design, Properties and Applications, Woodhead, Cambridge, UK, 2015.

[24] F. Pacheco-Torgal, C. Buratti, S. Kalaiselvam, C.G. Granqvist, V. Ivanov, editors, Nano and Biotech Based Materials for Energy Building Efficiency, Springer International Publishers, Cham, Switzerland, 2016.

[25] F. Pacheco-Torgal, E. Rasmussen, C.G. Granqvist, V. Ivanov, A. Kaklauskas, S. Makonin, editors, Start-Up Creation: The Smart Eco-Efficient Built Environment, Woodhead, Cambridge, UK, 2016.

[26] F. Pacheco-Torgal, C.G. Granqvist, B.P. Jelle, G.P. Vanoli, N. Bianco, J. Kurnitski, editors. CostEffective Energy Efficient Building Retrofitting: Materials, Technologies, Optimization and Case Studies, Woodhead, Cambridge, UK, 2017.

[27] B. Obama, The irreversible momentum of clean energy: private-sector efforts help drive decoupling of emissions and economic growth, Science 355 (2017) 126-129.

[28] J.S.E.M. Svensson, C.G. Granqvist, Electrochromic coatings for "smart windows", Sol. Energy Mater. 12 (1985) 391-402.

[29] C.G. Granqvist, Chromogenic materials for transmittance control of large-area windows, Crit. Rev. Solid State. Phys. Mater. Sci. 16 (1990) 291-308.

[30] C.M. Lampert, C.G. Granqvist, editors, Large-Area Chromogenics: Materials and Devices for Transmittance Control, SPIE Institutes for Advanced Optical Technologies, Vol. 4, SPIE Opt. Engr. Press, Bellingham, WA, USA, 1990.

[31] C.G. Granqvist, Electrochromics for smart windows: oxide-based thin films and devices, Thin Solid Films 564 (2014) 1-38.

[32] A. Azens, C.G. Granqvist, Electrochromic smart windows: energy efficiency and device aspects, J. Solid State Electrochem. 7 (2003) 64-68.

[33] E.S. Lee, D.L. DiBartolomeo, S.E. Selkowitz, Daylighting control performance of a thin-film ceramic electrochromic window: field study results, Energy Build. 38 (2006) 30-44.

[34] E.S. Lee, S.E. Selkowitz, R.D. Clear, D.L. DiBartolomeo, J.H. Klems, L.L. Fernandes, G.J. Ward, V. Inkarojrit, M. Yazdanian, Advancement of Electrochromic Windows, California Energy Commission, PIER, Publication number CEC-500-2006-052, 2006.

[35] J.-M. Dussault, L. Gosselin, T. Galstian, Integration of smart windows into building design for reduction of yearly overall energy consumption and peak loads, Sol. Energy 86 (2012) 3405-3416.

[36] M. Pittaluga, Electrochromic glazing and walls for reducing building cooling needs, in: F. Pacheco-Torgal, J.A. Labrincha, L.F. Cabeza, C.G. Granqvist, editors, Eco-Efficient Materials for Mitigating Building Cooling Needs: Design, Properties and Applications, Woodhead, Cambridge, UK, 2015, pp. 473-497.

[37] N. DeForest, A. Sherabi, J. O’Donnell, G. Garcia, J. Greenblatt, E.S. Lee, S. Selkowitz, D.J. Milliron, United States energy and $\mathrm{CO}_{2}$ savings potential from deployment of near-infrared electrochromic window glazings, Build. Environm. 89 (2015) 107-117. 
[38] N. DeForest, A. Sherabi, S. Selkowitz, D.J. Milliron, A comparative energy analysis of three electrochromic glazing technologies in commercial and residential buildings, Appl. Energy 192 (2017) 95-109.

[39] P.F. Tavares, A.R. Gaspar, A.G. Martins, F. Frontini, The impact of electrochromic windows on the energy performance of buildings in Mediterranean climates: a case study, in: F. Pacheco-Torgal, J.A. Labrincha, L.F. Cabeza, C.G. Granqvist, editors, Eco-Efficient Materials for Mitigating Building Cooling Needs: Design, Properties and Applications, Woodhead, Cambridge, UK, 2015, pp. 499-524.

[40] C. Baldassarri, A. Shehabi, F. Asdrubali, E. Masanet, Energy and emissions analysis of next generation electrochromic devices, Sol. Energy Mater. Sol. Cells 156 (2016) 170-181.

[41] R.D. Clear, V. Inkarojrit, E.S. Lee, Subject responses to electrochromic windows, Energy Build. 38 (2006) 758-779.

[42] M. Zinzi, Office worker preferences of electrochromic windows: a pilot study, Build. Environm. 41 (2006) 126-1273.

[43] A. Piccolo, F. Simone, Performance requirements for electrochromic smart window, J. Build. Engr. 3 (2015) 94-103.

[44] P. Eichholtz, N. Kok, J.M. Quigley, Doing well by doing good? Green office buildings, Am. Econ. Rev. 100 (2010) 2492-2509.

[45] C.M. Lampert, Electrochromic materials and devices for energy efficient windows, Sol. Energy Mater. 11 (1984) 1-27.

[46] J.S.E.M. Svensson, C.G. Granqvist, Electrochromic tungsten oxide films for energy efficient windows, Sol. Energy Mater. 11 (1984) 29-34.

[47] B.P. Jelle, A. Hynd, A. Gustavsen, D. Arasteh, H. Goudey, R. Hart, Fenestration today and tomorrow: a state-of-the-art review and future research opportunities, Sol. Energy Mater. Sol. Cells 96 (2012) 1-28.

[48] B.P. Jelle, Electrochromic smart windows for dynamic daylight and solar energy control in buildings, in: R.J. Mortimer, D.R. Rosseinsky, P.M.S. Monk, editors, Electrochromic Materials and Devices, Wiley-VCH, Weinheim, Germany, 2015, pp. 419-502.

[49] J. Mardaljevic, R.K. Waskett, B. Painter, Electrochromic glazing in buildings: a case study, in: R.J. Mortimer, D.R. Rosseinsky, P.M.S. Monk, editors, Electrochromic Materials and Devices, WileyVCH, Weinheim, Germany, 2015, pp. 571-592.

[50] C.J. Barile, D.J. Slotcavage, J. Hou, M.T. Strand, T.S. Hernandez, M.D. McGehee, Dynamic windows with neutral color, high contrast, sand excellent durability using reversible metal electrodeposition, Joule 1 (2017) 133-145.

[51] D. Barrios, R. Vergaz, J.M. Sanchez-Pena, C.G. Granqvist, G.A. Niklasson, Toward a quantitative model for suspended particle devices: optical scattering and absorption coefficients, Sol. Energy Mater. Sol. Cells 111 (2013) 115-122.

[52] D. Cupelli, F.P. Nicoletta, S. Manfredi, G. De Filpo, G. Chidichimo, Electrically switchable chromogenic materials for external glazing, Sol. Energy Mater. Sol. Cells 93 (2009) 329-333.

[53] K. Yoshimura, C. Langhammer, B. Dam, Metal hydrides for smart window and sensor applications, MRS Bull. 38 (2013) 495-503. 
[54] A. Llordés, G. Garcia, J. Gasquez, D.J. Milliron, Tunable near-infrared and visible-light transmittance in nanocrystal-in-glass composites, Nature 500 (2013) 323-326.

[55] A. Llordés, E.L. Runnerstrom, S.D. Lounis, D.J. Milliron, Plasmonic electrochromism in metal oxide nanocrystals, in: R.J. Mortimer, D.J. Rosseinsky, P.M.S. Park, editors, Electrochromic Materials and Devices, Wiley-VCH, Weinberg, Germany, 2015, pp. 363-397.

[56] S.-Y. Li, G.A. Niklasson, C.G. Granqvist, Plasmon-induced near-infrared electrochromism based on transparent conducting nanoparticles: approximate performance limits, Appl. Phys Lett. 101 (2012) 071903/1-071903/3.

[57] H.J. Byker, Solution-phase electrochromic devices and systems, in: R.J. Mortimer, D.J. Rosseinsky, P.M.S. Park, editors, Electrochromic Materials and Devices, Wiley-VCH, Weinberg, Germany, 2015, pp. 401-418.

[58] P.M. Beaujuge, J.R. Reynolds, Color control in $\pi$-conjugated organic polymers for use in electrochromic devices, Chem. Rev. 110 (2010) 268-320.

[59] A.L. Dyer, A.M. Österholm, D.E. Shen, K.E. Johnson, J.R. Reynolds, Conjugated electrochromic poymers: structure-driven colour and processing control, in: R.J. Mortimer, D.J. Rosseinsky, P.M.S. Park, editors, Electrochromic Materials and Devices, Wiley-VCH, Weinberg, Germany, 2015, pp. $113-183$.

[60] K.-C. Ho, C.-W. Hu, T.S. Varley, Electrochromic devices based on metal hexacyanometallate/viologen pairings, in: R.J. Mortimer, D.J. Rosseinsky, P.M.S. Park, editors, Electrochromic Materials and Devices, Wiley-VCH, Weinberg, Germany, 2015, pp. 91-112.

[61] P.M.S. Monk, D.R. Rosseinsky, R.J. Mortimer, Electrochromic materials and devices based on viologens, in: R.J. Mortimer, D.J. Rosseinsky, P.M.S. Park, editors, Electrochromic Materials and Devices, Wiley-VCH, Weinberg, Germany, 2015, pp. 57-89.

[62] Freedonia, World Flat Glass Market, The Freedonia Group, Cleveland, OH, USA, 2014.

[63] J. Wyszecki, W.S. Stiles, Color Science: Concepts and Methods, Quantitative Data and Formulae, second ed,. Wiley, New York, NY, USA, 2000.

[64] ASTM, G173-03 standard tables of reference solar spectral irradiances: direct normal and hemispherical on a $37^{\circ}$ tilted surface, in: Annual Book of ASTM Standards, American Society for Testing and Materials, Philadelphia, PA, USA, 2008, Vol 14.04.

[65] C.G. Granqvist, Oxide-based chromogenic coatings and devices for energy efficient fenestration: brief survey and update on thermochromics and electrochromics, J. Vac. Sci. Technol. B 32 (2014) 060801/1-060801/13.

[66] C.G. Granqvist, Recent progress in thermochromics and electrochromics: a brief survey, Thin Solid Films 614 (2016) 90-96.

[67] C.G. Granqvist, Electrochromic metal oxides: an introduction to materials and devices, in: R.J. Mortimer, D.R. Rosseinsky, P.M.S. Monk, editors, Electrochromic Materials and Devices, WileyVCH, Weinheim, Germany, 2015, pp. 3-40.

[68] A. Azens, G. Gustavsson, R. Karmhag, C.G. Granqvist, Electrochromic devices on polyester foil, Solid State Ionics 165 (2003) 1-5.

[69] A. Azens, E. Avendaño, J. Backholm, L. Berggren, G. Gustavsson, R. Karmhag, G.A. Niklasson, 
A. Roos, C.G. Granqvist, Flexible foils with electrochromic coatings: scinece, technology and applications, Mater. Sci. Engr. B 119 (2005) 214-223.

[70] C.G. Granqvist, Electrochromic foil: a case study, in: R.J. Mortimer, D.R. Rosseinsky, P.M.S. Monk, editors, Electrochromic Materials and Devices, Wiley-VCH, Weinheim, Germany, 2015, pp. $527-544$.

[71] C.G. Granqvist, İ. Bayrak Pehlivan, G.A. Niklasson, Electrochromics on a roll: web-coating and lamination for smart windows, Surf. Coatings Technol., http://dx.doi.org/10.1016/j.surfcoat.2017.08.006.

[72] A.M. Andersson, C.G. Granqvist, J.R. Stevens, Electrochromic $\mathrm{Li}_{x} \mathrm{WO}_{3} /$ polymer laminate $/ \mathrm{Li}_{y} \mathrm{~V}_{2} \mathrm{O}_{5}$ device: toward an all-solid-state smart window, Appl. Opt. 28 (1989) 3295-3302.

[73] S. Passerini, B. Scrosati, A. Gorenstein, A.M. Andersson, C.G. Granqvist, An electrochromic window based on $\mathrm{Li}_{x} \mathrm{WO}_{3} /(\mathrm{PEO})_{8} \mathrm{LiClO}_{4} / \mathrm{NiO}$, J. Electrochem. Soc. 136 (1989) 3394-3395.

[74] S.K. Deb, Optical and photoelectric properties and colour centres in thin films of tungsten oxide, Philos. Mag. 27 (1973) 801-822.

[75] C.G. Granqvist, Transparent conductors as solar energy materials: a panoramic review, Sol. Energy Mater. Sol. Cells 91 (2007) 1529-1598.

[76] D.S. Ginley, H. Hosono, H., D.C. Paine, editors, Handbook of Transparent Conductors, Springer Science+Business Media, New York, NY, USA, 2010.

[77] F. Lin, J.B. Bult, S. Nanayakara, A.C. Dillon, R.M. Richards, J.L. Blackburn, C. Engtrakul, Graphene as an efficient interfacial layer for electrochromic devices, ACS Appl. Mater. Interfaces 7 (2015) 11330-11336.

[78] F. Lin, D. Nordlund, T.-C. Weng, R.G. Moore, D.T. Gillaspie, K.M. Jones, A.C. Dillon, R.M. Richards, C. Engtrakul, Solid-state conversion reaction to enhance charge transfer in electrochromic materials, Adv. Mater. Interfaces 2 (2015) 1400523/1-1400523/6.

[79] S. Bogati, A. Georg, W. Graf, Photoelectrochromic devices based on sputtered $\mathrm{WO}_{3}$ and $\mathrm{TiO}_{2}$ films, Sol. Energy Mater. Sol. Cells 163 (2017) 170-177.

[80] R.-T. Wen, C.G. Granqvist, G.A. Niklasson, Eliminating degradation and uncovering iontrapping dynamics in electrochromic $\mathrm{WO}_{3}$ thin films, Nat. Mater. 14 (2015) 996-1001.

[81] R.-T. Wen, M.A. Arvizu, M, Morales-Luna, C.G. Granqvist, G.A. Niklasson, Ion trapping and detrapping in amorphous tungsten oxide thin films observed by real-time electro-optical monitoring, Chem. Mater. 28 (2016) 4670-4676.

[82] A. Talledo, C.G. Granqvist, Electrochromic vanadium-pentoxide-based films: structural, electrochemical, and optical properties, J. Appl. Phys. 77 (1995) 4655-4666.

[83] I. Lykissa, S.-Y. Li, M. Ramzan, S. Chakraborty, R. Ahuja, C.G. Granqvist, G.A. Niklasson, Electronic density-of-states of amorphous vanadium pentoxide films: Electrochemical data and density functional calculations, J. Appl. Phys. 115 (2014) 183701/1-183701/5.

[84] D. Vernardou, Using an atmospheric pressure chemical vapor deposition process for the development of $\mathrm{V}_{2} \mathrm{O}_{5}$ as electrochromic material, Coatings 7 (2017) 24/1-24/11.

[85] A. Azens, G. Vaivars, M. Veszelei, L. Kullman, C.G. Granqvist, Electrochromic devices embodying W oxide/Ni oxide tandem films, J. Appl. Phys. 89 (2001) 7885-7887. 
[86] G.A. Niklasson, C.G. Granqvist, Electrochromics for smart windows: thin films of tungsten oxide and nickel oxide, and devices based on these, J. Mater. Chem. 17 (2007) 127-156.

[87] T. Nanba, I. Yasui, X-ray diffraction study of microstructure in amorphous tungsten trioxide films prepared by electron beam vacuum evaporation, J. Solid State Chem. 83 (1989) 304-315.

[88] C.A. Triana, C. Moyses Araujo, R. Ahuya, G.A. Niklasson, T. Edvinsson, Disentangling the intricate atomic short-range order and electronic properties in amorphous transition metal oxides, Sci. Rep. 7 (2017) 2044/1-2044/12.

[89] S. Maleknia, J. Brodbelt, K. Pope, Characterization of the reactive and dissociative behavior of transition metal oxide cluster ions in the gas phase, J. Am. Soc. Mass Spectrom. 2 (1991) 212-219.

[90] L. Sai, L. Tang, X. Huang, G. Chen, J. Zhao, J. Wang, Lowest-energy structures of $\left(\mathrm{WO}_{3}\right)_{n}(2 \leq n$ $\leq 12)$ clusters from first-principles global search, Chem. Phys. Lett. 544 (2012) 7-12.

[91] K. Qi, X. Li, M. Sun, Q. Huang, J. Wei, Z. Xu, W. Wang, X. Bai, E. Wang, In-situ transmission electron microscopy imaging of formation and evolution of $\mathrm{Li}_{x} \mathrm{WO}_{3}$ during lithiation of $\mathrm{WO}_{3}$ nanowires, Appl. Phys. Lett. 108 (2016) 233103/1-233103/4.

[92] J.A. Thornton, High-rate thin film growth, Ann. Rev. Mater. Sci. 7 (1977) 239-60.

[93] I. Petrov, P.B. Barna, L. Hultman, J.E. Greene, Microstructural evolution during film growth, J. Vac. Sci. Technol. A21 (2003) S117-S128.

[94] A. Anders, A structure zone diagram including plasma-based deposition and ion etching, Thin Solid Films 518 (2010) 4087-4090.

[95] M.M. Hawkeye, M.T. Taschuk, M.J. Brett, Glancing Angle Deposition of Thin Films: Engineering the Nanoscale, Wiley, Hoboken, NJ, USA, 2014.

[96] A. Barranco, A. Borras, A.R. Gonzalez-Elipe, A. Palmero, Perspectives on oblique angle deposition of thin films: from fundamentals to devices, Progr. Mater. Sci. 76 (2016) 59-153.

[97] J. Gil-Rostra, M. Cano, J.M. Pedrosa, F.J. Ferrer, F. García-García, F. Yubero, F., A.R. GonzálezElipe, Electrochromic behavior of $\mathrm{W}_{x} \mathrm{Si}_{y} \mathrm{O}_{z}$ thin films prepared by reactive magnetron sputtering at normal and glancing angles, ACS Appl. Mater. Interfaces 4 (2012) 628-638.

[98] R. Giannuzzi, M. Balandeh, A. Mezzetti, L. Meda, P. Pattathil, G. Gigli, F. Di Fonzo, M. Manca, On the Li intercalation kinetics in tree-like $\mathrm{WO}_{3}$ electrodes and their implementation in fast switchable electrochromic devices, Adv. Opt. Mater. 3 (2015) 1614-1622.

[99] J. Kim, G.K. Ong, Y. Wang, G. LeBlanc T.E. Williams, T.M. Mattox, B.A. Helms, D.J. Milliron, Nanocomposite architecture for rapid spectrally-selective electrochromic modulation of solar transmittance, Nano Lett. 15 (2015) 5574-5579.

[100] R.-T. Wen, C.G. Granqvist, G.A. Niklasson, Anodic electrochromism for energy-efficient windows: cation/anion-based surface processes and effects of crystal facets in nickel oxide thin films, Adv. Funct. Mater. 25 (2015) 3359-3370.

[101] A. Hjelm, C.G. Granqvist, J.M. Wills, Electronic structure and optical properties of $\mathrm{WO}_{3}$, $\mathrm{LiWO}_{3}, \mathrm{NaWO}_{3}$, and $\mathrm{HWO}_{3}$, Phys. Rev. B 54 (1996) 2436-2445.

[102] G.A. de Wijs, R.A. de Groot, Structure and electronic properties of amorphous $\mathrm{WO}_{3}$, Phys. Rev. B 60 (1999) 16463-16474. 
[103] N. Bondarenko, O. Eriksson, N.V. Skorodumova, Polaron mobility in oxygen-deficient and lithium-doped tungsten trioxide, Phys. Rev. B 92 (2015) 165119/1-165119/8.

[104] C.A. Triana, C.G. Granqvist, G.A. Niklasson, Electrochromism and small-polaron hopping in oxygen deficient and lithium intercalated amorphous tungsten oxide films, J. Appl. Phys. 118 (2015) 024901/1-024901/9.

[105] H. Hamdi, E.K.H. Salje, P. Ghosez, E. Bousquet, First-principles reinvestigation of bulk $\mathrm{WO}_{3}$, Phys. Rev. B 94 (2016) 245124/1-245124/11.

[106] L. Berggren, G.A. Niklasson, Optical charge transfer absorption in lithium-intercalated tungsten oxide thin films, Appl. Phys. Lett. 88 (2006) 081906/1-081906/3.

[107] L. Berggren, J.C. Jonsson, G.A. Niklasson, Optical absorption in lithiated tungsten oxide thin films: experiment and theory, J. Appl. Phys. 102 (2007) 083538/1-083538/7.

[108] E. Avendaño, A. Azens, G.A. Niklasson, C.G. Granqvist, Proton diffusion and electrochromism in hydrated $\mathrm{NiO}_{y}$ and $\mathrm{Ni}_{1-x} \mathrm{~V}_{x} \mathrm{O}_{y}$ thin films, J. Electrochem. Soc. 152 (2005) F203-F212.

[109] E. Avendaño, H. Rensmo, A. Azens, A. Sandell, G. de M. Azevedo, H. Siegbahn, G.A. Niklasson, C.G. Granqvist, Coloration mechanism in proton-intercalated electrochromic hydrated $\mathrm{NiO}_{y}$ and $\mathrm{Ni}_{1-x} \mathrm{~V}_{x} \mathrm{O}_{y}$ thin films, J. Electrochem. Soc. 156 (2009) P132-P138.

[110] J.B. Goodenough, Metallic oxides, in: Reiss, H., editor, Progress in Solid State Chemistry, Pergamon, Oxford, UK, 1971, Vol. 5, pp. 145-399.

[111] A. Gavrilyuk, U. Tritthart, W. Gey, Photoinjection of hydrogen and the nature of a giant shift of the fundamental absorption edge in highly disordered $\mathrm{V}_{2} \mathrm{O}_{5}$ films, Phys. Chem. Chem. Phys. 13 (2011) 9490-9497.

[112] O.F. Schirmer, V. Wittwer, G. Baur, G. Brandt, Dependence of $\mathrm{WO}_{3}$ electrochromic absorption on crystallinity, J. Electrochem. Soc. 124 (1977) 749-753.

[113] J. Ederth, A. Hoel, G.A. Niklasson, C.G. Granqvist, Small polaron formation in porous $\mathrm{WO}_{3-x}$ nanoparticle films, J. Appl. Phys. 96 (2004) 5722-5726.

[114] J.-G. Zhang, D.K. Benson, C.E. Tracy, S.K. Deb, A.W. Czanderna, C. Bechinger, Chromic mechanism in amorphous $\mathrm{WO}_{3}$ films, J. Electrochem. Soc. 144 (1997) 2022-2026.

[115] S. Darmawi, S. Burkhardt, T. Leichtweiss, D.A. Weber, S. Wenzel, J. Janek, M.T. Elm, P.J. Klar, Correlation of electrochromic properties and oxidation states in nanocrystalline tungsten trioxide, Phys. Chem. Chem. Phys. 17 (2015) 1590-15911.

[116] H.G. Reik, D. Heese, Frequency dependence of the electrical conductivity of small polarons for high and low temperatures, J. Phys. Chem. Solids 28 (1967) 581-596.

[117] V.V. Bryksin, Optical intraband absorption in disordered systems during strong electron-phonon interaction, Fiz. Tverd. Tela 24 (1982) 1110-1117 [English translation: Soviet Phys. Solid State 24 (1982) 627-631].

[118] D. Zhou, B. Che, J. Kong, X. Lu, A nanocrystalline tungsten oxide electrochromic coating with excellent cycling stability prepared via a complexation-assisted sol-gel method, J. Mater. Chem. C 4 (2016) 8041-8051.

[119] M.A. Arvizu, C.A. Triana, B.I. Stefanov, C.G. Granqvist, G.A. Niklasson, Electrochromism in sputter-deposited W-Ti oxide films: durability enhancement due to Ti, Sol. Energy Mater. Sol. Cells 
[120] R.-T. Wen, G.A. Niklasson, C.G. Granqvist, Strongly improved electrochemical cycling durability by adding iridium to electrochromic nickel oxide films, ACS Appl. Mater. Interfaces, 7 (2015) 9319-9322.

[121] R.-T. Wen, G.A. Niklasson, C.G. Granqvist, Electrochromic iridium-containing nickel oxide films with excellent electrochemical performance, J. Electrochem. Soc. 163 (2016) E7-E13.

[122] M.A. Arvizu, G.A. Niklasson, C.G. Granqvist, Electrochromic $\mathrm{W}_{1-x-y} \mathrm{Ti}_{x} \mathrm{Mo}_{y} \mathrm{O}_{3}$ thin films made by sputter deposition: large optical modulation, good cycling durability, and approximate color neutrality, Chem. Mater. 29 (2017) 2246-2253.

[123] S. Hashimoto, H. Matsuoka, Lifetime and electrochromism of amorphous $\mathrm{WO}_{3}-\mathrm{TiO}_{2}$ thin films, J. Electrochem. Soc. 138 (1991) 2403-2408.

[24 S. Hashimoto, H. Matsuoka, Prolonged lifetime of electrochromism of amorphous $\mathrm{WO}_{3}-\mathrm{TiO}_{2}$ thin films, Surface Interface Anal. 19 (1992) 464-468.

[125] B.W. Faughnan, R.S. Crandall, Optical properties of mixed-oxide $\mathrm{WO}_{3} / \mathrm{MoO}_{3}$ electrochromic films, Appl. Phys. Lett. 31 (1977) 834-836.

[126] Y.S. Lin, T.H. Tsai, S.C. Hung, S.W. Tien, Enhanced lithium electrochromism of atmospheric pressure plasma jet-synthesized tungsten/molybdenum oxide films for flexible electrochromic devices, J. Solid State Electrochem. 17 (2013) 1077-1088.

[127] M.A. Arvizu, C.G. Granqvist, G.A. Niklasson, Electrochromism in sputter deposited $\mathrm{W}_{1-y} \mathrm{Mo}_{y} \mathrm{O}_{3}$ thin films, J. Phys.: Conf. Ser. 682 (2016) 012005/1-012005/6.

[128] D. Gillaspie, A. Norman, C.E. Tracy, J.R. Pitts, S.-H. Lee, A. Dillon, Nanocomposite counter electrode materials for electrochromic windows, J. Electrochem. Soc. 157 (2010) H328-H331.

[129] F. Lin, D. Nordlund, T.-C. Weng, R.G. Moore, D.T. Gillaspie, A.C. Dillon, R.M. Richards, C. Engtrakul, Hole doping in Al-containing nickel oxide materials to improve electrochromic performance, ASC Appl. Mater. Interfaces 5 (2013) 301-309.

[130] F. Lin, D. Nordlund, T.-C. Weng, D. Sokaras, K.M. Jones, R.B. Reed, D.T. Gillaspie, D.G.J. Weir, R.G. Moore, A.C. Dillon, R.M. Richards, C. Engtrakul, Origin of electrochromism in highperforming nanocomposite nickel oxide, ACS Appl. Mater. Interfaces 5 (2013) 3643-3649.

[131] Y.-S. Lin, P.-Y. Chuang, P.S. Shie, Lithium electrochromic performance of flexible Ni oxide films enhanced by $\mathrm{Fe}$ oxide addition with an atmospheric pressure plasma jet for flexible electrochromic application, J. Solid State Electrochem. 19 (2015) 1671-1683.

[132] J. Zhou, G. Luo, Y. Wei, J. Zheng, C. Xu, Enhanced electrochromic performances and cycle stability of NiO-based thin films via Li-Ti co-doping prepared by sol-gel method, Electrochim. Acta 186 (2015) 182-191.

[133] I.Y. Cha, S.H. Park, J.W. Lim, S.J. Yoo, Y.-E. Sung, The activation process through a bimodal transmittance state for improving electrochromic performance of nickel oxide thin film, Sol. Energy Mater. Sol. Cells 108 (2013) 22-26.

[134] C.G. Granqvist, S. Green, G.A. Niklasson, N.R. Mlyuka, S. von Kræmer, P. Georén, Advances in chromogenic materials and devices, Thin Solid Films 518 (2010) 3046-3053. 
[135] Y. Zhang, S.-H. Lee, A. Mascarenhas, S.K. Deb, An UV-photochromic memory effect in proton-based $\mathrm{WO}_{3}$ electrochromic devices, Appl. Phys. Lett. 93 (2008) 203508/1-203508/2.

[136] C.G. Granqvist, S. Green, E.K. Jonson, R. Marsal, G.A. Niklasson, A. Roos, Z. Topalian, A. Azens, P. Georén, G. Gustavsson, R. Karmhag, J. Smulko, L.B. Kish, Electrochromic foil-based devices: optical transmittance and modulation range, effect of ultraviolet irradiation, and quality assessment by $1 / f$ current noise, Thin Solid Films 516 (2008) 5921-5926.

[137] Y. Wang, J. Kim, Z. Gao, O. Zandi, S. Heo, P. Banerjee, D.J. Milliron, Disentangling photochromism and electrochromism by blocking hole transfer at the electrolyte interface, Chem. Mater. 28 (2016) 7198-7202.

[138] H. Miyazaki, T. Matsuura, T. Ota, Nickel oxide-based photochromic composite films, J. Ceram. Soc. Jpn. 124 (2016) 1175-1177.

[139] A. Jonsson, A. Roos, E.K. Jonson, The effect on transparency and light scattering of dip coated antireflection coatings on window glass and electrochromic foil, Sol. Energy Mater. Sol. Cells 94 (2010) 992-997.

[140] İ. Bayrak Pehlivan, C.G. Granqvist, R. Marsal, P. Georén, G.A. Niklasson, [PEI-SiO $]$ ]:[LiTFSI] nanocomposite polymer electrolytes: ion conduction and optical properties, Sol. Energy Mater. Sol. Cells 98 (2012) $465-471$.

[141] İ. Bayrak Pehlivan, E.L. Runnerstrom, S.-Y. Li, G.A. Niklasson, D.J. Milliron, C.G. Granqvist, A polymer electrolyte with high luminous transmittance and low solar throughput: polyethyleneiminelithium bis(trifluoromethylsulfonyl) imide with $\mathrm{In}_{2} \mathrm{O}_{3}$ :Sn nanocrystals, Appl. Phys. Lett. 100 (2012) 241902/1-241902/4.

[142] İ. Bayrak Pehlivan, R. Marsal, E. Pehlivan, E.L. Runnerstrom, D.J. Milliron, C.G. Granqvist, G.A. Niklasson, Electrochromic devices with polymer electrolytes functionalized by $\mathrm{SiO}_{2}$ and $\mathrm{In}_{2} \mathrm{O}_{3}: \mathrm{Sn}$ nanoparticles: rapid coloration/bleaching dynamics and strong near-infrared absorption, Sol. Energy Mater. Sol. Cells 126 (2014) 241-247.

[143] I. Hamberg, C.G. Granqvist, Evaporated Sn-doped $\mathrm{In}_{2} \mathrm{O}_{3}$ films: basic optical properties and applications to energy-efficient windows, J. Appl. Phys. 60 (1986) R123-R159.

[144] G.A. Niklasson, C.G. Granqvist, O. Hunderi, Effective medium models for the optical properties of inhomogeneous materials, Appl. Opt. 20 (1981) 26-30.

[145] C.G. Granqvist, Progress in oxide-based electrochromics: towards roll-to-roll manufacturing, Mater. Res. Soc. Symp. Proc. 1315 (2012) 89-100.

[146] C.A. Bishop, Vacuum Deposition onto Webs, Films and Foils, third edition, William Andrew, Waltham, MA, USA. 2015.

[147] C.A. Bishop, Roll-to-Roll Vacuum Deposition of Barrier Coatings, second edition, Wiley, Hoboken, NJ, USA, 2015.

[148] M.E. Badding, S.C. Schulz, L.A. Michalski, R. Budziak, Performance and durability testing of lithium-ion monolithic electrochromic glazings, in: K.-C. Ho, C.B. Greenberg, D.A. MacArthur, editors, Electrochromic Materials III, PV 96-24, The Electrochemical Society, Pennington, NJ, USA, 1997, pp. 369-384.

[149] A.W. Czanderna, D.K. Benson, G.J. Jorgensen, J.-G. Zhang, C.E. Tracy, S.K. Deb, Durability issues and service lifetime prediction of electrochromic windows for buildings applications, Sol. Energy Mater. Sol. Cells 56 (1999) 419-436. 
[150] C.M. Lampert, A. Agrawal, C. Baertlien, J. Nagai, Durability evaluation of electrochromic devices: an industry perspective, Sol. Energy Mater. Sol. Cells 56 (1999) 449-463.

[151] J. Nagai, G.D. McMeeking, T. Saitoh, Durability of electrochromic glazing, Sol. Energy Mater. Sol. Cells 56 (1999) 309-319.

[152] N. Sbar, M. Badding, R. Budziak, K. Cortez, L. Laby, L. Michalski, T. Ngo, S Schulz, K. Urbanik, Progress toward durable, cost effective electrochromic window glazing, Sol. Energy Mater. Sol. Cells 56 (1999) 321-341.

[153] T. Kubo, J. Tanimoto, M. Minami, T. Toya, Y. Nishikitani, H. Watanabe, Performance and durability of electrochromic windows with carbon-based counter electrode and their application in the architectural and automotive fields, Solid State Ionics 165 (2003) 97-104.

[154] R.-T. Wen, C.G. Granqvist, G.A. Niklasson, Cyclic voltammetry on sputter-deposited films of electrochromic Ni oxide: power-law decay of the charge density exchange, Appl. Phys. Lett. 105 (2014) 163502/1-163502/4.

[155] R.-T. Wen, C.G. Granqvist, G.A. Niklasson, Anodic electrochromic nickel oxide thin films: decay of charge density upon extensive electrochemical cycling, ChemElectroChem 3 (2016) 266-275 [Corrigendum in ChemElectroChem 3 (2016) 675].

[156] R.-T. Wen, S. Malmgren, C.G. Granqvist, G.A. Niklasson, Degradation dynamics for electrochromic $\mathrm{WO}_{3}$ films under extended charge insertion/extraction: unveiling physicochemical mechanisms, ACS Appl. Mater. Interfaces 9 (2017) 12872-12877.

[157] A. Plonka, Dispersive kinetics, Annu. Rep. Prog. Chem. Sect. C 97 (2001) 91-147.

[158] R.-T. Wen, G.A. Niklasson, C.G. Granqvist, Sustainable rejuvenation of electrochromic $\mathrm{WO}_{3}$ films, ACS Appl. Mater. Interfaces 7 (2015) 28100-28104.

[159] R.-T. Wen, G.A. Niklasson, C.G. Granqvist, Eliminating electrochromic degradation in amorphous $\mathrm{TiO}_{2}$ through Li-ion detrapping, ACS Appl. Mater. Interfaces, 8 (2016) 5777-5782.

[160] M.A. Arvizu, C.G. Granqvist, G.A. Niklasson, Rejuvenation of degraded electrochromic $\mathrm{MoO}_{3}$ thin films made by DC magnetron sputtering: preliminary results. J. Phys.: Conf. Ser. 764 (2016) 012009/1-012009/6.

[161] J. Bisquert, Analysis of the kinetics of ion intercalation: ion trapping approach to the solid-state relaxation processes, Electrochim. Acta 47 (2002) 2435-2449.

[162] J. Bisquert, V.S. Vikhrenko, Analysis of the kinetics of ion intercalation: two state model describing the coupling of solid state ion diffusion and ion binding processes, Electrochim. Acta 47 (2002) 3977-3988.

[163] J. Bisquert, Fractional diffusion in the multiple-trapping regime and revision of the equivalence with the continuous-time random walk, Phys. Rev. Lett. 91 (2003) 010602/1-010602/4.

[164] J. Bisquert, Beyond the quasistatic approximation: impedance and capacitance of an exponential distribution of traps, Phys. Rev. B 77 (2008) 235203/1-235203/15.

[165] M.A. Arvizu, R.-T. Wen, D. Primetzhofer, J.E. Klemberg-Sapieha, L. Martinu, G.A. Niklasson, C.G. Granqvist, Galvanostatic ion detrapping rejuvenates oxide thin films, ACS Appl. Mater. Interfaces 7 (2015) 26387-26390. 
[166] B. Baloukas, M.A. Arvizu, R.-T. Wen, G.A. Niklasson, C.G. Granqvist, R. Vernhes, J.E. Klemberg-Sapieha, L. Martinu, Galvanostatic rejuvenation of electrochromic $\mathrm{WO}_{3}$ thin films: ion trapping and detrapping observed by optical measurements and by time-of-flight secondary ion mass spectroscopy, ACS Appl. Mater. Interfaces 9 (2017) 16995-17001.

[167] H.-Y. Qu, D. Primetzhofer, M.A. Arvizu, Z. Qiu, U. Cindemir, C.G. Granqvist, G.A. Niklasson, Electrochemical rejuvenation of anodically coloring electrochromic nickel oxide thin films, to be published (2017).

[168] C.-P. Li, C. Engtrakul, R.C. Tenent, C.A. Wolden, Scalable synthesis of improved nanocrystalline, mesoporous tungsten oxide films with exceptional electrochromic performance, Sol. Energy Mater. Sol. Cells 132 (2015) 6-14.

[169] P.J. Wojcik, L. Santos, L. Pereira, R. Martins, E. Fortunato, Tailoring nanoscale properties of tungsten oxide for inkjet printed electrochromic devices, Nanoscale 7 (2015) 1696-1708.

[170] E. Alonso, A.M. Sherman, T.J. Wallington, M.P. Everson, F.R. Field, R. Roth, R.E. Kirchain, Evaluating rare earth element availability: a case with revolutionary demand on clean technologies, Environm. Sci. Technol. 46 (2012) 3406-3414.

[171] M. Fernandes, R. Leones, A.M.S. Costa, M.M. Silva, S. Pereira, J.F. Mano, E. Fortunato, R. Rego, V. de Zea Bermudez, Electrochromic devices incorporating biohybrid electrolytes doped with a lithium salt, an ionic liquid or a mixture of both, Electrochim. Acta 161 (2015) 226-235.

[172] M. Fernandes, R. Leones, S. Pereira, A.M.S. Costa, J.F. Mano, M.M. Silva, E. Fortunato, V. de Zea Bermudez, R. Rego, Eco-friendly sol-gel derived sodium-based ormolytes for electrochromic devices, Electrochim. Acta 232 (2017) 484-494.

[173] G. Cai, J. Wang, J., P.S. Lee, Next-generation multifunctional electrochromic devices, Acc. Chem. Res. 49 (2016) 1469-1476.

[174] Y. Huang, M. Zhu, Y. Huang, Z. Pei, H. Li, Z. Wang, Q. Xue, C. Zhi, Multifunctional energy storage and conversion devices, Adv. Mater. 28 (2016) 8344-8364.

[175] A. Cannavale, P. Cossari, G.E. Eperon, S. Colella, F. Fiorito, G. Gigli, H.J. Snaith, A. Listori, Forthcoming perspectives on photoelectrochromic devices: a critical review, Energy Environ. Sci. 9 (2016) 2682-2719.

[176] F. Bella, G. Leftheriotis, G. Griffini, G. Syrrokostas, S. Turri, M. Grätzel, C. Geribaldi, A new design paradigm for smart windows: photocurable polymers for quasi-solid photoelectrochromic devices with excellent long-term stability under real outdoor operating conditions, Adv. Funct. Mater. 26 (2016) 1127-1137.

[177] G. Cai, X. Wang, M. Cui, P. Darmawan, J. Wang, A.L.-S. Eh, P.S. Lee, Electrochromosupercapacitor based on direct growth of NiO nanoparticles, Nano Energy 12 (2015) 258-267.

[178] L. Shen, L. Du, S. Tan, Z. Zang, C. Zhao, W. Mai, Flexible electrochromic supercapacitor hybrid electrodes based on tungsten oxide films and silver nanowires, Chem. Commun. 52 (2016) 6296-6299.

[179] P. Yang, P. Sun, Z. Chai, L. Huang, X. Cai, S. Tan, J. Song, W. Mai, Large-scale fabrication of pseudocapacitive glass windows that combine electrochromism and energy storage, Angew. Chem. Int. Ed. 53 (2014) 11935-11939.

[180] P. Yang, P. Sun, W. Mai, Electrochromic energy storage devices, Mater. Today 19 (2016) 394 402. 
[181] D. Zhou, F. Shi, D. Xie, D.H. Wang, X.H. Xia, X.L. Wang, C.D. Gu, J.P. Tu, Bi-functional Modoped $\mathrm{WO}_{3}$ nanowire array electrochromism-plus-electrochemical energy storage, J. Colloid Interface Sci. 465 (2016) 112-120.

[182] G. Luo, L. Shen, J. Zheng, C. Xu, A europium ion doped $\mathrm{WO}_{3}$ film with the bi-functionality of enhanced electrochromic switching and tunable red emission, J. Mater. Chem. C 5 (2017) 3488-3494.

[183] G. Garcia, R. Buonsanti, E.L. Runnerstrom, R.J. Mendelsberg, A. Llordes, A. Anders, T.J. Richardson, D.J. Milliron, Dynamically modulating the surface plasmon resonance of doped semiconductor nanocrystals, Nano Lett. 11 (2011) 4415-4420.

[184] A. Llordés, Y. Wang, A. Fernandez-Martinez, P. Xiao, T. Lee, A. Poulain, O. Zandi, C.A. Saez Cabezas, G. Henkelman, D.J. Milliron, Linear topology in amorphous metal oxide electrochromic networks obtained via low-temperature solution processing, Nat. Mater. 15 (2016) 1267-1273.

[185] E.L. Runnerstrom, A. Llordés, S.D. Lounis, D.J. Milliron, Nanostructured electrochromic smart windows: traditional materials and NIR-selective plasmonic nanocrystals, Chem. Commun. 50 (2014) 10555-10572.

[186] T.E. Williams, C.M. Chang, E.L. Rosen, G. Garcia, E.L. Runnerstrom, B.L. Williams, B. Koo, R. Buonsanti, D.J. Milliron, B.A. Helms, NIR-selective electrochromic heteromaterial frameworks: a platform to understand mesoscale transport phenomena in solid-state electrochemical devices, J. Mater. Chem. C 2 (2014) 3328-3335.

[187] Y. Wang, E.L. Runnerstrom, D.J. Milliron, Switchable materials for smart windows, Annu. Rev. Chem. Biomol. Engr. 7 (2016) 283-304.

[188] S.-Y. Li, G.A. Niklasson, C.G. Granqvist, Nanothermochromics: calculations for $\mathrm{VO}_{2}$ nanoparticles in dielectric hosts show much improved luminous transmittance and solar energy transmittance modulation, J. Appl. Phys. 108 (2010) 063525/1-063525/5.

[189] S.-Y. Li, G.A. Niklasson, C.G. Granqvist, Thermochromic fenestration with $\mathrm{VO}_{2}$-based materials: three challenges and how they can be met, Thin Solid Films 520 (2012) 3823-3828.

[190] S.-Y. Li, G.A. Niklasson, C.G. Granqvist, Thermochromic undoped and Mg-doped $\mathrm{VO}_{2}$ thin films and nanoparticles: optical properties and performance limits for energy efficient windows, J. Appl. Phys. 115 (2014) 053513/1-053513/10.

[191] Y.-X. Ji, M. Boman, G.A. Niklasson, C.G. Granqvist, Thermochromics for energy-efficient buildings: thin surface coatings and nanoparticle composites, in: F. Pacheco-Torgal, C. Buratti, S. Kalaiselvam, C.G. Granqvist, V. Ivanov, V., editors, Nano and Biotech Based Materials for Energy Building Efficiency, Springer International Publishers, Cham, Switzerland, 2016, pp. 71-96.

[192] C.G. Granqvist, A. Azens, P. Heszler, L.B. Kish, L. Österlund, Nanomaterials for benign indoor environments: electrochromics for "smart" windows, sensors for air quality, and photo-catalysis for air cleaning, Sol. Energy Mater. Sol. Cells, 91 (2007) 355-365.

[193] B.I. Stefanov, J. Maibach, Z. Topalian, G.A. Niklasson, C.G. Granqvist, L. Österlund, Improving the sustained photocatalytic activity of anatase $\mathrm{TiO}_{2}$ thin films for indoor air cleaning: synergistic effects of preferential $<001>$ orientation and sulfate and nitrate functionalization, unpublished report, 2017.

[194] K.-M. Koch, editor, Membrane Structures, Prestel, Munich, Germany, 2014.

[195] A. LeCuyer, ETFE: Technology and Design, Birkhäuser, Basel, Switzerland, 2008. 
[196] J. Fahlteich, C. Steiner, S. Amberg-Schwab, K.J. Dreichmann, O. Miesbauer, M. Mirza, K. Noller, More than just protection: surface functionalization of fluoropolymer films for exterior applications, Kunststoffe Int. (12) (2015) 45-48.

[197] W. Skorupa, H. Schmidt, H., editors, Subsecond Annealing of Advanced Materials: Annealing by Lasers, Flash Lamps and Swift Heavy Ions, Springer, Berlin Heidelberg, Germany, 2014.

[198] S. Weller, M. Junghähnel, Flash lamp annealing of ITO thin films on ultra-thin glass: improvement of the electrical and optical properties, Vacuum in Forschung und Praxis 27(4) (2015) $29-33$. 